\title{
Artificial intelligence approaches for spatial prediction of landslides in mountainous regions of western India
}

PANKAJ PRASAD ( $\square$ ppankaj.earthscience@gmail.com )

National Institute of Oceanography CSIR https://orcid.org/0000-0002-3118-2201

Victor Joseph Loveson

National Institute of Oceanography CSIR

Sumit Das

University of Pune: Savitribai Phule Pune University

Priyankar Chandra

Banaras Hindu University

\section{Research Article}

Keywords: Landslide susceptibility, Boruta, GIS, Machine learning, Western India

Posted Date: August 13th, 2021

DOI: https://doi.org/10.21203/rs.3.rs-251440/v1

License: (9) This work is licensed under a Creative Commons Attribution 4.0 International License.

Read Full License 
1 Title: Artificial intelligence approaches for spatial prediction of landslides in mountainous regions

2 of western India

3 Pankaj Prasad ${ }^{1 *}$, Victor Joseph Loveson ${ }^{1}$, Sumit Das $^{2}$, Priyankar Chandra ${ }^{3}$

$4 \quad{ }^{1}$ Geological Oceanography Division, CSIR- National Institute of Oceanography, Dona Paula-

5 403004, Goa, India

$6{ }^{2}$ Department of Geography, Savitribai Phule Pune University, Pune 411007, Maharashtra, India

$7 \quad{ }^{3}$ Department of Geography, Institute of Science, Banaras Hindu University, Varanasi-221005,

8 Uttar Pradesh, India

\section{1 *Corresponding Author}

12 Pankaj Prasad

13 Email: ppankaj.earthscience@gmail.com; ppankaj@nio.org

14 Mobile No.: +919883329432

15

16

\section{Acknowledgement}

18 We acknowledge the support from the University Grant Commission (3160 NET-June 2015) to 19 the first author. The authors are thankful to the Director CSIR-NIO for constant encouragement. 20 The authors are also grateful to the reviewer for critical comments and constructive suggestions 21 that improved the manuscript significantly. Field support from the survey team members is 22 thankfully acknowledged. The NIO contribution number is.......... 
The prediction of landslide is a complex task but preparing the landslide susceptibility map through artificial intelligence approaches can reduce life loss and damages resulting from landslides. The purpose of this study is to evaluate and compare the landslide susceptibility mapping (LSM) using six machine learning models, including random forest (RF), deep boost (DB), stochastic gradient boosting (SGB), rotation forest $(\mathrm{RoF})$, boosted regression tree (BRT), and logit boost (LB) in the mountainous regions of western India. The landslide inventory map consisting of 184 landslide locations has been divided into two groups for training (70\% dataset) and validation (30\% dataset) purposes. Fourteen landslide triggering factors including slope, topographical roughness index, road density, topographical wetness index, elevation, slope length, drainage density, stream power index, geomorphology, rainfall, soil, lithology, lineament density, and normalized difference vegetation index have been considered using the boruta approach for the LSM. The results reveal that the RF model has the highest precision in terms of AUC $(0.88 ; 0.89)$, kappa $(0.62 ; 0.50)$, accuracy $(0.81 ; 0.77)$, and specificity $(0.86 ; 0.86)$ both in the study region and secondary region, respectively. Hence, it can be concluded that the RF is an effective and promising technique as compared to DB, SGB, RoF, BRT, and LB for landslide susceptibility assessment in the research area as well as in regions having similar geo-environmental configuration.

Keywords: Landslide susceptibility; Boruta; GIS; Machine learning; Western India

\section{Introduction}

Globally, the frequency of natural disasters has been dramatically increased over the last few decades (UNISDR, 2015). Each year, a loss of billions of dollars and thousands of lives due to natural disasters, such as earthquakes, tsunamis, cyclones, floods, and landslides are recorded (Yesilnacar and Topal, 2005; Yilmaz, 2009). Almost there is no region in this earth which is free from the impact of such devastating natural hazards (Suzen and Doyuran, 2003). The occurrence of landslides constitutes about $17 \%$ of the natural disasters worldwide as reported by the Center for Research on the Epidemiology of Disasters (Pourghasemi et al., 2012; Nohani et al., 2019). Yilmaz (2009) and Pourghasemi et al. (2012) believe that landslide events will tend to rise in the next decades owing to deforestation, land-use change, and changing climatic condition. Many scientists have assessed landslide hazards and delineated the high-risk zones in past few decades. 
In general, landslide mapping techniques can be divided into two major methods, i.e. direct and indirect. In case of direct mapping, geomorphologists determine the degree of susceptibility based on the experience and knowledge of terrain characteristics, hillslopes etc. (Van et al., 2003). However, indirect mapping utilizes different statistical or high-performance deterministic machine learning or hybrid models to predict the landslide probable areas on the basis of previous landslide distribution. In the preceding two decades, multitudes of LSM studies have been undertaken with increasing popularity of Geographic Information System (Aleotti and Chowdury, 1999; Guzzetti et al., 2006).

66
The pioneering works of the landslide mapping were done in 1970s (Carrara et al., 1977; Brabb et al., 1978). Since then, various approaches and methods have been put forwarded and employed for LSM, including heuristic terrain and susceptibility zoning, geomorphological mapping, statistical modelling, physically-based numerical modelling etc. (Montgomery and Dietrich, 1994; Hansen et al., 1995; Aleotti and Chowdhury, 1999; Guzzeti et al., 1999; Lee et al., 2001; Van et al., 2008; Reichenbach et al., 2018). However, the above approaches are no longer capable because they were restricted to large amounts of field data in a smaller area. From the beginning of the current century, statistical modelling with high-resolution GIS data has been in use in different geographical regions for LSM, including frequency ratio (Yilmaz, 2009; Nohani et al., 2019), logistic regression (Pourghasemi et al., 2013; Zhao and Chen, 2020), weight of evidence (Lee et al., 2004a; Regmi et al., 2010). The statistical methods are less accurate compared to the machine learning methods because it can overcome the statistical limitations and predict non-linear structures (Tehrany et al., 2013; Costache and Bui, 2019; Prasad et al., 2020). Hence, in recent years, several machine learning models have been developed and applied successfully for LSM, including random forest (Kim et al., 2018; Arabameri et al., 2019), rotation forest (Hong et al., 2018; Pham et al., 2020a), support vector machine (Chen et al., 2017; Phong et al., 2019), boosted regression tree (Youssef et al., 2016; Park and Kim, 2019), naive bayes (Bui et al., 2012; Pham et al., 2020a), adaboost (Hong et al., 2018; Wu et al., 2020), and artificial neural network (Lee et al., 2004b; Yilmaz, 2009). Such methods have also been employed in various spatial prediction mapping, viz. flood susceptibility (Khosravi et al., 2018; Pham et al., 2020b; Shahabi et al., 2020), land subsidence (Bui et al ., 2018; Oh et al., 2019), gully erosion (Amiri et al.,2019; Pourghasemi et al., 2020; Chen et al., 2021b), piping erosion (Hosseinalizadeh et al., 2019; Chen et al., 2021), 
land-use change (Aburas et al., 2019; Jamali. 2020), and groundwater potentiality (Rahmati et al., 2016; Naghibi et al., 2019). Besides statistical and machine learning models, novel models with high accuracy have been also used in landslide mapping (Bui et al., 2017; Nguyen et al., 2017; Abedini et al., 2019; Chen et al., 2020; Chen and Li., 2020; Pham et al., 2020a).

In the aforementioned studies, the performance of the applied models has been assessed with respect to particular study regions. It is imperative to show the model applicability in another region for general findings (Prasad et al., 2020). To the best of our knowledge, in landslide susceptibility mapping, the models have been validated by applying them in more than one geographic region. Thus, the present study aims to map the landslide-prone zones in the western India through different approaches of artificial intelligence and to validate the models in another region. In spite of being a high landslide prone area, the present area of investigation has not received much attention from the researchers. The current study is the first attempt to prepare the landslide susceptibility map hereof using machine learning approaches. The LSM is foremost mitigative step to reduce the havoc fatalities and infrastructural damages as a dire consequence of frequent severe landslides along the precarious Ghats escarpment triggered by torrential rainfall during the Indian Summer Monsoon. In addition to the comparison of different machine learning approaches, the scientific delineation of landslide-prone regions will be helpful for proper planning and management of the study area.

\section{Study area and GIS database}

\subsection{Study area}

The study area lying approximately between $17^{\circ} 50$ to $18^{\circ} 19$ North latitudes and $73^{\circ} 18$ to $73^{\circ} 40$ East longitudes, comprises an approximate area of $1180 \mathrm{~km}^{2}$ (Fig. 1). The study region represents a hilly topography ranging from $4 \mathrm{~m}$ to $1404 \mathrm{~m}$ above the mean sea level. The average slope of the area is about $15^{\circ}$, though some areas are close to the vertical slope. The study area shows a general tilting facing towards the Arabian Sea.

Geologically, the area spans from upper Cretaceous to lower Eocene, which comes under the Sahyadri group of formation. From the geomorphological perspective, more than fifty percent of the area belongs to structural origin highly and moderately dissected plateau. The climatic condition of the study region is subtropical monsoon type. The minimum and maximum average 
117 temperatures of the area are $25^{\circ} \mathrm{C}$ and $30^{\circ} \mathrm{C}$, respectively. The Arabian branch of south-west 118 monsoon brings huge amount of cloud that leads to intense orographic rainfall along the hilly 119 slopes. The area receives about $3000 \mathrm{~mm}$ annual mean rainfall during the monsoon seasons (June120 September) (Department of Agriculture, Maharashtra State). The principal river Savitri, descends 121 from the Mahabaleshwar peak of Western Ghats and flows for about $110 \mathrm{~km}$ before it empties into 122 the Arabian sea.

125 Inventory data is crucial for any natural hazard mapping especially to understand the landslide 126 distribution and effective variables (Kadavi et al., 2018; Panahi et al., 2020). In the present study, 127 the landslide locations were collected from the Public Works Department (PWD) office, Google 128 Earth historical images and intensive field survey (Fig. 2). A total of 184 landslide locations were taken into account for this study. The dataset was divided into two groups 70\% (129 locations) as 130 training data for model fitting and the rest 30\% (55 locations) as testing data for model predictive 131 capability assessment (Fig. 1). Simultaneously, an equal number of non-landslide localities were recognized from the topographical map, field survey, and satellite images for the purpose of model establishment. Likewise, the inventory map of another region was generated (Fig. 1).

\subsubsection{Landslide triggering factors}

The important step for the LSM is to prepare a spatial database of landslide conditioning factors (Reichaenbach et al., 2018; Nohani et al., 2019). The predisposing variables of the landslide were selected after extensive literature survey and field investigation (Hong et al., 2018; Wang et al., 2019). These factors are: slope, elevation, slope length (LS), topographical wetness index (TRI), stream power index (SPI), topographical wetness index (TWI), drainage density (DD), road density (RD), lineament density (LD), normalized difference vegetation index (NDVI), rainfall, lithology, geomorphology, and soil (Fig. 3a-3n). The terrain variables (elevation, slope, LS, SPI, TWI, and TRI) were extracted from the SRTM digital elevation model (DEM) with $30 \mathrm{~m}$ spatial resolution. Each conditioning variable was transformed into a spatial database of $30 \times 30 \mathrm{~m}$ size 
144

145

146

147

148

149

150

151

152

153

154

155

156

157

158

159

160

161

162

163

164

165

166

167

168

169

170

and the grid of the study region was generated by 1337 columns and 1740 rows (1312960 pixels; $\left.1180 \mathrm{~km}^{2}\right)$.

The slope is one of the most important triggering variables since it directly influences the landslide occurrences (Yalchin, 2008). The slope map of the study region was categorized into five classes: $0-7.19,7.19-15.25,15.25-24.18,24.18-35.98$, and 35.98-73.40 degrees. The altitude of the area is classified into five classes. LS represents slope steepness and slope length of the topography, which affects the soil loss potential (Naghibi et al., 2019). The LS values are extracted by the given mathematical formula (Moore and Burch, 1986).

$L S=(A \times \text { cellsize } / 22.13)^{0.4} \times(\sin \theta / 0.0896)^{1.3}$

here $A$ and $\theta$ indicate the flow accumulation and slope values in degree, respectively.

The ratio between the land surface and flat surface in a specific area is defined as TRI (Stambaugh and Guyette, 2008). TRI map are derived from the following formula

$T R I=A b s\left(\max ^{2}-\min ^{2}\right)$

where maximum and minimum altitude are written as max and min, respectively.

SPI and TWI are vital hydrological factors for LSM. The erosive power and discharge in a specific area are expressed by SPI (Moore and Grayson, 1991; Chapi et al., 2017). TWI is defined as the ratio between the catchment area and slope (Gallant, 2000; Chapi et al., 2017). Both variables were calculated from the catchment area $(A)$ and slope $(\beta)$ by the given formulae (Moore et al., 1991).

$S P I=A \times \tan \beta$

$T W I=\operatorname{In}(A / \tan \beta)$

The stability of slope is controlled by the saturation level of material, which is indirectly related to the drainage density (Yalchin, 2008). The construction of roads beside high slope area reduces burden on both the heel of slope and topography that causes landslide (Yalchin, 2008). Lineament is the linear or curvilinear feature on the earth surface (Das et al., 2018). It represents weak zones where the slope instability leads to the landslide. Lineament map of the study area was prepared from the shaded relief maps. The density maps of drainage, road, and lineament were prepared in Arc GIS 10 environment using spatial analyst tools. 
171 To prepare the NDVI thematic layer, band 4 (red band) and band 5 (infrared) of Landsat 8 OLI

172 (https://earthexplorer.usgs.gov/) image (date: 29.10.2018) were used. The NDVI value was

173 extracted as follows:

$174 \quad N D V I=(N I R-R) /(N I R+R)$

175

176

177

178

179

180

181

182

183

184

185

186

187

188

189

190

191

192

193

194

195

196

197

where NIR and R denote the infrared and red bands of the electromagnetic spectra, respectively.

The lithology map obtained from the Geological Society of India (GSI) was reclassified into four broad categories: Karla, Indrayani, Diveghat, and Purandgarh formation on 1:250000 scale. The geomorphology map of the study area was reclassified into five major groups namely, structural origin moderately dissected plateau (SoMDp), structural origin highly dissected plateau (SoHDp), structural origin low dissected plateau (SoLDp), denudational origin moderately dissected lower plateau (DoMDLp), denudational origin-pediment pediplain complex (DoPPc) on 1:50000 based on Landsat 8 image, NRSC base map, topographical maps and field survey scale. The thematic map of soil was modified using the base map of the National Bureau of Soil Survey and Land Use planning (NBSSLUP) on 1: 500,000 scale. The soil map was categorized into three broad classes: Typic Ustorthents, Lithic Ustorthents, and Udic Rhodustalfs . Rainfall has been the most influential factor in landslide occurrences especially in the Indian sub-continent due to arrival of the southwest monsoon. The rainfall data of the last five years (2013-2018) was collected from the rain gauge stations of the department of agriculture, Maharashtra state. Based on this data, rainfall map was classified into four classes using the inverse distance weighted method. Among the classification methods, natural break method was extensively applied for classification of landslide variables (Phong et al., 2019; Chen and Chen, 2021). In the present study, natural break method was used for the classification of the causative factors of landslide in ArcGIS platform.

\section{Methodology}

The methodology flow-chart of the present study is presented in Figure 4.

\subsection{Boruta and multicollinearity feature selection methods}

Variable selection is the essential function in natural hazard mapping. The factor determination method improves the model performance by increasing the data quality and reducing noise, 
198

199

200

201

202

203

204

205

206

207

208

209

210

211

212

213

214

215

216

217

218

219

220

221

222

223

224

225

226

overfitting, dimensionality of feature space and preventing redundancy problems (Bui et al., 2019). There are two popular features choosing methods for modeling including wrapper and filter accessible. In the present study, the boruta algorithm was used for feature selection based on wrapper method. The classification in boruta approach is implemented by voting of multiple unbiased weak classifier decision trees. The scale of importance of the variable is obtained as the loss of classification accuracy due to the random alternate of factor values between aims. The algorithm works as follows: (i) At the first step, it adds randomness to the dataframe by shuffling each feature which are called shadow feature (ii) Then, it trains the RF classifier to measure the $\mathrm{Z}$ score values and checks whether the attribute has a higher $\mathrm{Z}$ score than the maximum $\mathrm{Z}$ score among shadow attributes (MZSA). (iii) Finally, the features having value less than MZSA are rejected for being irrelevant and vice versa (Kursa and Rudnicki, 2010; Amiri et al., 2019; Prasad et al., 2021). Shadow minimum, mean, and maximum values represent the $Z$ score of a shadow attribute. On the other hand, tentative variables lying close to the maximum shadow (maximum $\mathrm{Z}$ score), are confirmed or rejected based on the mean shadow (mean Z score).

In addition, multicollinearity analysis was performed to verify the results of boruta method. Multicollinearity is the popular statistical method to find out whether any positive correlation between the conditioning factors exists or not. Researchers like Chen et al. (2018a), Pourghasemi et al. (2020) showed that the influencing variables containing the variance inflation factors (VIF) value more than 5 and tolerance (TOL) value less than 0.2 were subjected to multicollinearity while in the studies of Nguyen et al. (2017), Wang et al. (2019) the VIF value $>10$ or TOL value $<0.1$ of the controlling factors were rejected.

\subsection{Landslide events and variable inter-relationship by Weight of evidence (WoE) method}

The WoE is a quantitative approach used to forecast the occurrence of hazard events (Armas, 2012). Based on Bayes rule, the approach was primarily propounded for mineral potential mapping (Bonham-carter, 1994; Chen et al., 2018a). With the march of time, WoE approach was popularized in other spatial prediction mapping (Rahmati et al., 2015; Aghdam et al., 2017; Chen et al., 2018a; Arabameri et al., 2018). In this study, WoE method was used to determine the correlation between the landslide events and effective parameters. The primary purpose of this model is to measure the positive $\left(W_{i}^{+}\right)$and negative weights $\left(W_{i}^{-}\right)$. 
$227 \quad W_{i}^{+}=\operatorname{In}\left[\frac{P(B \mid A)}{P(B \mid \bar{A}}\right]$

$228 \quad W_{i}^{-}=\operatorname{In}\left[\frac{P(\bar{B} \mid A)}{P(\bar{B} \mid \bar{A}}\right]$

229 where $\mathrm{P}$ and $\mathrm{ln}$ stand for the probability and natural logarithm, respectively. B and $\bar{B}$ indicate the 230 presence and absence of desired sub-class of landslide predisposing factors, respectively whereas 231 A and $\overline{\mathrm{A}}$ are the presence and absence of landslide events, respectively.

Random forest introduced by Breiman (2001), is a non-parametric method for classification and regression analysis, The RF algorithm creates many decision trees to enhance the performance of the model (Breimen, 2001; Rahmati et al., 2016). Each decision tree is originated by bootstrap samples and leaves around one-third of samples for validation purpose using the out of bag (OOB) error. The advantages of the model are: i) large dataset handling, ii) no overfitting, iii) OOB error estimation, iv) low bias and low variance, v) no requirement of prior data transformation and rescaling, vi) higher prediction performance. To tune the model, the algorithm requires two important criteria: number of trees $\left(\mathrm{n}_{\text {tree }}\right)$ and number of features $\left(\mathrm{m}_{\text {try }}\right)$.

Deep boost is a new ensemble learning algorithm formulated by Cortes, Mohri, and Syed (2014). The method is updated and some new solutions that are left about the theory underlying AdaBoost.

243 It consists of deep decision trees or members of complex families. The method is a capacityconscious criterion to achieve high accuracy without overfitting the data. The advantage of the algorithm is to minimize the corresponding learning bound and the mixture weight assigned to 246 each sub-family (Cortes et al., 2014; Chen et al., 2021). The algorithm can extend by examining 247 non-differentiable convex surrogate losses. As far as we are concerned, the DB model has been 248 used for the first time in natural hazard mapping.

249 Stochastic gradient boosting is an ensemble machine learning technique that merges both 250 the advantages of bagging and boosting methods and is used for classification and regression 251 purpose (Friedman, 2001, 2002; Zhou et al., 2016). SGB is the modification of adaboost and 252 adabtive bagging method. SGB has many advantages such as i) it uses random sub-sample 
(selected without replacement) of the dataset at each stage of boosting process instead of the whole dataset, ii) at each step, small trees are generated rather than large entire classification trees, iii) since small trees are developed, SGB method is highly resistant to overfitting iv) the steepest gradient algorithm of the model is resistant to outliers (Friedman, 2002; Lawrence et al., 2004; Moisen et al., 2006).

Rotation forest is an ensemble learning method devised by Rodriguez et al. (2006) to enhance the predictive performance of individual classifiers. In this method, every single classifier is merged with one another and each classifier may be trained using different i) training datasets; ii) subsets of features; iii) parameters of the classifier; or iv) classifier models (Polikar et al., 2010; Nguyen et al., 2017). The model is a combination of the random subspace and bagging method with principal component analysis (PCA) for the ensemble classifier. By applying PCA technique, the training dataset was randomly classified into K subsets (Rodriguez et al., 2006; Nguyen et al., 2017; Naghibi et al., 2019).

Boosted regression tree utilizes both machine learning and statistical techniques for classification and regression problems (Youssef et al., 2016; Naghibi et al., 2016). BRT algorithm uses boosting technique to combine a large number of simple tree for maximizing the predictive capacity (Elith et al., 2008; Naghibi et al., 2019). The advantages of this model are: i) it replaces the missing data using surrogates, ii) it can deal with any type of predictive variable (numeric, categorical, binary), iii) the predictive value get affected by monotone transformation, and different scales of measurement. To run the BRT model, three parameters are required to optimize it, namely interaction depth, shrinkage or learning rate, and number of trees. Interaction depth represents the number of nodes and the shrinkage indicates the contribution of trees.

Logit Boost developed by Friedman and Tibshirani (2000), uses boosting method to reduce the bias and variance (Oh et al., 2019). The LB method is a minor variation of popular boosting technique (Adaboost). In this method, the additive logistic regression function is used to classify the dataset (Tehrany et al., 2018). The main advantages of the LB technique are: i) it can handle noisy data, ii) it has the ability to reduce the training errors, iii) it is used for the multiclass tasks (Oh et al., 2019). The vector values of the model define the input variables and two output groups (landslide and non-landslide events). 
283 Validation is an imperative stage in machine learning modelling for the evaluation of the study, without which the models have not any scientific significance (Rahmati et al., 2016; Naghibi et al., 2016; Prasad at al., 2020). In the validation dataset, dependent variables are not considered for verifying the model efficiency to predict the location of landslides. In the present study, the models were validated based on a set of quantitative parameters such as accuracy, kappa index, sensitivity, specificity, and area under the receiver operating characteristics curve (AUROC). These quantitative criteria were assessed using the possible consequences (PC), namely true positive TP), false positive (FP), true negative (TN), and false negative (FN). The detailed information of these quantitative parameters is available in Chapi et al. (2017).

The ROC curve is a scientific method to examine the overall performance of the models (Rahmati et al., 2016; Chapi et al., 2017; Bui et al., 2019). The AUROC is a quantitative index for model capability to predict correctly the occurrence or non-occurrence of specific events. AUC value lying in between 0 to 1 , was classified as poor $(0.5-0.6)$, average $(0.6-0.7)$, good (0.7-0.8), very good (0.8-0.9), and excellent (0.9-1) (Chen et al., 2018b). The higher AUC value, more will be the model perfection (Chapi et al., 2017; Naghibi et al., 2017; Das 2019, 2020). AUROC value is calculated as follows:

$$
A U R O C=\sum T P+\sum T N /(P+N)
$$

here the $\mathrm{P}$ and $\mathrm{N}$ refer to the total numbers of landslide occurrences and non-landslide occurrences in the study area, respectively.

\section{Results}

4.1 Feature selection and important landslide triggering variables

The selection of significant conditioning factors in machine learning techniques is of vital importance to improve model accuracy by eliminating impertinent factors (Khosravi et al., 2018; Bui et al., 2019). In the current research, the boruta technique was used for the relevant variable selection. From the nineteen landslide predisposing factors, boruta evaluation elected fourteen suitable variables (slope, TRI, RD, TWI, elevation, LS, DD, SPI, geomorphology, rainfall, soil, 
lithology, LD, and NDVI) whereas five factors including standard curvature, plan curvature, profile curvature, land-use, and aspect were removed (Fig 5a). These rejected variables were also excluded in the study of Chen et al., 2018b. The boruta approach is capable of determining the mean, median, minimum, and maximum importance of the factors displayed in Table 1. In congruence with the result of boruta algorithm, the result of multicollinearity analysis presented in Table 2, showed that the standard, plan and profile curvature were disqualified since there VIF value exceeded 10 and TOL fell below 0.1 .

After choosing the significant factors that are crucial for the modelling, the variable importance function of RF method was used to measure the feature importance for LSM in the study area. The measured importance values of the landslide conditioning variables were 100 (slope), 94.49 (TRI), 65.99 (elevation), 56.98 (TWI), 56.34 (LS), 46.26 (DD), 44.56 (RD), 41.99 (rainfall), 34.84 (SPI), 33.47 (NDVI), 27.54 (LD), 22.04 (geomorphology), 8.44 (soil), and 0 (lithology). These results of the variable importance analysis revealed that the slope, TRI, elevation, and TWI had more influence on landslides, followed by LS, DD, RD, rainfall, SPI, NDVI, LD, geomorphology, soil, and lithology (Fig 5b). From the literature, it was noticed that the contribution of the conditioning factors in a particular region varies with the use of different measuring methods (Chen et al., 2018b). In the case of present study, variable importance results of both boruta and RF methods were almost same that confirmed the predictive ability of the algorithms.

\subsection{Spatial interaction of landslides and conditioning factors using WoE model}

The spatial interconnection between landslide events and affecting variables applying WoE method is presented in Table 3. In this table, $\mathrm{C} / \mathrm{SC}$ value is the final weight used for the above relationship. The $\mathrm{C} / \mathrm{SC}$ value of the present study was lying between -9.60 and 9.11 . The higher positive value shows strong correlation between landslide events and conditioning factors, whereas negative weight indicates poor relation. Regarding slope, increasing slope angle is directly related to the landslide events in a certain range (Bui et al., 2017; Chen and Chen, 2021). This fact was reflected from the current research where most of the landslide happened in the higher slope angle classes viz. $4^{\circ}-34^{\circ}$ and $35^{\circ}-73^{\circ}$ with 8.87 and $7.69 \mathrm{C} / \mathrm{SC}$ values, respectively whereas lower slope angle held negative weights. The elevation is another significant factor of landslide events as shown in the study of Wang et al. (2019) and Arabameri et al., (2019). The analysis of WoE for 
landslide events and elevation expressed that the moderate elevation $(430-713 \mathrm{~m})$ recorded the maximum C/SC value (9.11). On the other side, lower $(4-154 \mathrm{~m})$ and higher $(920-1404 \mathrm{~m})$ elevation classes had negative weights. The increasing slope length is favorable for water infiltration into sub-soil that enhances the possibility of slope failure (Bui et al., 2017). The LS value was highest (7.61) in the class of $0.42-2.10$, indicating strong relation with landslide occurrences. The weight of the $\mathrm{C} / \mathrm{SC}$ went upward with increasing topographic roughness. The $\mathrm{C} / \mathrm{SC}$ values of sub classes $0.13-0.58,0.58-0.85$, and $0.85-1.23$ of TRI were $-9.60,7.41$, and 7.98, respectively. The zero value of all the classes of SPI made it clear that SPI had no relation with landslide events. The first class (2.23-5.68) of TWI contented the highest C/SC value (6.50) implying the presence of high soil moisture content rendered landslide probability high. The maximum weight (7.81) for DD was found in the second class (0.51-0.75), followed by $0.13-0.51$ (-1.08), 0.75-0.96 (-2.73), and 0.96-1.23 (-4.08). The region having positive DD value denoted greater chances of landslide occurrence. With respect to $\mathrm{RD}$, the $\mathrm{C} / \mathrm{SC}$ value (4.93) was observed as the highest in class 1.01-4.11 where more than forty five percent of landslides occurred. In the case of LD, results showed that the class of $0-0.28$ was the greatest weight of 2.50. A high vegetation density area minimizes the chance of landslide by reducing soil erosion and its transmission. As per NDVI results the 0.21-0.35 class contained the highest C/SC value (2.57) suggesting high susceptibility to landslides followed by -003-0.21 (1.32), 0.35-0.41 (-0.06), and 0.41-0.58 (-2.12). The longer period of monsoon rainfall in the study area had direct impact on landslide occurrence because of more runoff caused soil loosening and sediment flow. The maximal rainfall class $(619-656 \mathrm{~mm})$ in the area under study indicates that around fifty percent of landslides took place in this group. Regarding lithology, the highest weights were obtained from the bdd (3.31) and bdp (2.47) groups. Since, the rock of these groups belongs to 350-450 m elevation (landslide occurrence zone), it can be inferred that they are more weathered. For geomorphology, structural origin highly dissected plateau has strongly correlated with the landslide events of $\mathrm{C} / \mathrm{SC}$ value 6.97. This sub class also obtained maximum score by AHP method in the research of Bera et al., 2018. In the case of soil, Udic Rhodustalfs soil was only positive weight (6.21) among the soil groups.

\subsection{Model construction}


367 In machine learning models, researchers applied 10 cross-validation method in order to enhance the precision of classification and to reduce the noise (Wang et al., 2020). Therefore, the present work adopted this method with five repetitions using $70 \%$ of the landslide and non-landslide points. These points along with their extracted fourteen conditioning factor values comprised the training dataset whereas the remaining points were used for validation purpose. The exact pixel values of the derived parameters influenced the validation result due to the higher range of the values. To solve this problem, values were transformed into 0 to 1 range with the help of min-max normalization. After the model establishment with training dataset, testing dataset was utilized to verify the performance and predictive capability of each model. This complete procedure was done using the R and Arc GIS software.

\subsection{Performance and comparison of the models}

In this study, AUC and selected statistical measurements were used for evaluation of the models. These criteria considered both training and testing results for model comparison and application. The training dataset defines the model fitness whereas the testing dataset represents the predictive capability of the model (Bui et al., 2018; Prasad et al., 2021). In the case of training dataset, among the six models, the RF performed excellently with the highest value of 1 quantified by accuracy, Kappa, sensitivity, specificity, and AUC in both the primary and secondary study area (Table 4). Landis and Koch, (1977) determined that the kappa value $>0.8$ means the perfect match of measured value with observed value. The value of 1 for sensitivity and specificity represent that all landslide and non-landslide points were correctly classified. The AUC values of the remaining models for primary and secondary regions were 0.89, 0.99 (DB); 0.87, 1 (SBM); 0.95, 0.97 (RoF); 0.82, 0.89 (BRT); and 0.86, 1 (LB), respectively. The highest AUC value of RF method in both the region manifested the better goodness of fit compared to the rest.

The established models were corroborated with the testing dataset to check the predictive ability of the models. The results of validation dataset revealed that RF method held the highest as measured by accuracy (0.81), kappa (0.62), specificity (0.86), and AUC (0.88) compared to other models (Fig. 6a, Table 5). It is also observed that the RF model appeared to be ideal in the secondary region based on accuracy (0.77), kappa (0.50), specificity (0.86), and AUC (0.89) (Fig. $6 \mathrm{~b}$, Table 5). For primary and secondary regions, AUC values of the other models were $0.87 ; 0.82$ 
(DB), 0.84; 0.85 (SBM), 0.83; 0.82 (RoF), 0.86; 0.81 (BRT), and 0.77; 0.76 (LB) respectively. The comparative results from Tables 4 and 5 exhibited suitability of the models in the following descending manner: RF DB, SBM, RoF, BRT, and LB. The model's AUC values which were more than 0.8 (except LB) confirmed the high precision landslide susceptibility mapping in the areas of investigation. In a nutshell, RF model outperformed other models in both the regions.

\subsection{Landslide susceptibility map construction}

The preparation of the landslide susceptibility maps is essential to know the possibility of future landslide occurrences in an area. After the training processes, each pixel of the study area was computed for the prediction of landslide. These values ranging from 0 to 1 indicate low to high chances of landslide occurrences. In general, the classification of the derived probability values includes automatic and user-defined methods (Chen et al., 2021a). However, there are several standard techniques in GIS to reclassify the probability maps, namely natural breaks, min-max normalizations, standard deviations, equal intervals, geometrical, and quantiles. A specific method is selected based on the research objective and distribution of data (Chapi et al., 2017). It was learned from the previous studies that many researchers had employed the natural break method for generating the susceptibility maps (Hong et al., 2018; Park and Kim, 2019; Panahi et al., 2020; Chen et al., 2021a). This classification method has advantage of no class bias as well as minimum intra-class and maximum inter-class deviations (Arabameri et al., 2020). In the present work, the distribution of probability values of the models abruptly changed. For this reason, the landslide susceptibility maps were classified using the natural break method in ArcGIS environment into four groups, including low, moderate, high, and very high (Fig. 7). The low and moderate prone zones of the entire study area account for 22.74\%, 40.06 (RF); 30.08\%, 40.94\% (DB); 38.99\%, $30.37 \%(\mathrm{SBM}) ; 54.59 \%, 28.75 \%(\mathrm{RoF}) ; 57.13 \%, 15.93 \%$ (BRT); and 9.02\%, 28.8 (LB), respectively. The high susceptible classes of RF, DB, SBM, RoF, BRT, and LB models constitute $26.06 \%, 20.13 \%, 19.37 \%, 13.02 \%, 13.51 \%$, and $44.3 \%$ of the study region, respectively. The share of 10.58\% (RF), 8.83\% (DB), 11.25\% (SBM), 3.61\% (RoF), 13.42\% (BRT), and 17.85\% (LB) belong to very high vulnerable zones (Fig. 8). The lowest minimal variations of high and very high susceptibility classes indicate the high model precision (Naghibi et al., 2017; Prasad et al., 2020). In the present study, minuscule difference between RF, DB, and SBM, models with regard to high and very high landslide prone zones ensured the models high accuracy (Fig. 8). The low 
susceptibility classes of the RoF and BRT models occupied much larger area than the moderate susceptibility classes in compared to other models (except LB model). This is mainly on account of the fact that the degree of prediction varies model to model for their different algorithm. Regarding LB model, susceptible classes did not correspond with the classes of other models because of less precision in prediction. The study pointed out that the north-eastern, eastern, and south-eastern parts of the research area are more vulnerable to landslides owing to the steepness, roughness, and wetness of these mountainous regions.

\section{Discussion}

\subsection{Variable Contribution Analysis}

Although many studies have been accomplished worldwide on LSM, still there is no specific set of variables (Van et al., 2006; Chen and Li, 2020). The influencing factors vary from one study region to another due to heterogeneity of the earth. In the current study, a total of nineteen factors were chosen consulting recent studies carried out in the different regions with more or less same elevation as of the study area under consideration and subsequently fourteen relevant factors were selected based on boruta algorithm for LSM (Hong et al., 2018; Kadavi et al., 2018; Nohani et al., 2019; Arabameri et al., 2019; Wang et al., 2019). It is worth mentioning that the result of boruta approach almost matched with the result of multicollinearity which reflects the robustness of boruta algorithm in feature selection. It can be seen that the topographical factors such as slope, TRI, and elevation exerted more influence on landslide occurrences compared to the categorical factors (lithology, soil, and geomorphology) in the study area. Researcher inferred that topographical variables are the most responsible for landslide incidents (Nakileza and Nedala, 2020; Arabameri et al., 2020). This is because of the topographical factors mainly slope angle which plays a key role in slope stability and controls the shear and normal strength on the plane of weakness. The study area is basically more or less homogeneous bedrock region (Sahyadri group) with a thin veneer of top soil. Therefore, the factors lithology and soil did not have much influence on landslide occurrence. Most of the slides in this area that occurred within accessible locations are rock falls or debris flow. On the other side, WoE method expressed the influence variability of sub classes of each landslide governing factor. Based on the result, the highest $\mathrm{C} / \mathrm{SC}$ values noted from the slope and elevation sub classes revealed that the landslide occurrences mostly took place 
into moderate elevation $(430-713 \mathrm{~m})$ with higher slope angle $\left(24-73^{\circ}\right)$ probably due to more weathering at this height of the study area.

\subsection{Previous works and future work proposal}

Mathematically, landslide susceptibility is the likelihood of the occurrence of slope failures in location while the geo-environmental condition is fixed (Guzzeti et al., 2005). LSM is generally done to predict the potential geographic locations of future landslides (Guzzeti et al. 1999; 2006). In recent years, machine learning approaches have become more popular and outstripped other conventional methods in landslide susceptibility and hazard mapping (Bui et al., 2019; Arabameri et al., 2020). For the mapping of potential landslide locations, a large number of machine learning methods have been developed, artificial neural network (Lee et al., 2001), support vector machine (Dou et al., 2015), random forest (Miner et al., 2010), neuro-fuzzy (Pradhan, 2013), naïve bayes (Bui et al., 2012), quadratic discriminant (Rossi et al., 2010), adaptive neuro-fuzzy inference system-satin bowerbird optimizer (Chen et al., 2021a) just to name a few. However, there is no universal model for spatial mapping of landslide but the applied model can be appropriate for similar geo-environmental settings (Chen et al., 2020; Prasad et al., 2020). Therefore, the present study aims to select suitable method for LSM in the mountainous regions of western India. In this research, six machine learning approaches, including RF, DB, SBM, RoF, BRT, and LB were compared in the study area as well as in the secondary region to choose the significant model. Among these models, RF model showed the highest precision, consistent performance, and minimal difference between training and validation results, followed by DB, SBM, RoF, BRT, and LB for LSM in both the regions. The robustness of the RF method is also manifested in other spatial prediction mappings with very high precision (Catani et al., 2013; Naghibi et al., 2019; Costache et al., 2019; Amiri et al., 2019; Prasad at al., 2020). A study by Chen et al. (2018b) in Chongren County, China, located at about an elevation (1-1230 m) as of the current study area, RF model proved to be the most suitable with respect to the performance of other applied models in landslide prediction. Arabameri et al. (2018) found that the RF model was the best fit in the Gallicash River Watershed, Iran. Bera et al. (2018) worked on LSM in mountainous region of western India. In this study, accuracy of fuzzy gamma operator (81\%) and analytical hierarchy process (AHP) (69\%) models were lesser than the present research. In the above research works, the researchers employed several methods including novel model only to one respective study 
area, which restricted the applicability of the models. To widen applicability of the models, it is important to apply the selected models in alike geographic environment (Prasad et al., 2020). In the present study, the outcomes of the models were almost same for both the primary and secondary regions. Therefore, the comparability of the models remained consistent with the either regions under investigation. From the results, it can be stated that the RF model is appropriate for LSM in the western India and also in regions with similar geo-environmental conditions. Likely, in future, more researches are required to conduct in different geographical areas around the world for the assessment of applicability of machine learning models. Furthermore, it can be suggested that the integration of SAR and optical datasets may improve the precision of the models and help to identify the landslide points in a larger area.

\subsection{Advantages and disadvantages of the models}

The machine learning method is applied in natural hazard and resource mapping because of its unique advantageous capability of automatically performing the task of searching several datasets aimed at obtaining necessary information (Chen et al., 2020). It is also noted that the predictive accuracy of the model, to some extent, depends on the quality of data and the establishment of the model from training dataset (Nohani et al., 2019). In present study, an attempt was made to find out the probable reasons behind the better performance of RF method and comparatively poor achievement of LB model. RF method suitably fitted resulting in reduction of the error for validation dataset in the primary and secondary regions. The reason for better performance of the RF method may be due to composition of multiple decision trees and interconnection capability of conditioning variables and non-linearity (Catani et al., 2013; Prasad et al., 2020). Besides, RF method escapes the overfitting of dataset which is common problem in artificial intelligence approaches. In the case of LB method, the performance is relatively less in either region. The underperformance of LB model may be because of i) steady property indicated by logistic loss, ii) any change of output value does not affect the loss value, iii) oversimplification in model establishment can reduce the validation accuracy, iv) problem in node spit gain and value fitting (Sun et al., 2014).

\section{Conclusions}


513 The Landslide susceptibility mapping through high performing artificial intelligence models is a 514 indispensable step for downscaling future loss of properties and human lives. Therefore, in this 515 study, six machine learning approaches (RF, DB, SGB, RoF, BRT, and LB) were employed for 516 effective LSM. To confirm the model applicability, the selected methods were tested in another 517 region as well. The major findings of the study are as follows:

518 i) Among the nineteen landslide causing factors, fourteen (slope, elevation, LS, SPI, TRI, TWI, 519 RD, LD, DD, NDVI, rainfall, lithology, soil, and geomorphology) were selected and remaining 520 five (aspect, land-use, plan curvature, profile curvature and standard curvature) were discarded 521 with the help of boruta approach for LSM.

522 ii) From the attribute evaluation of WoE method, it was found that the landslide events mostly 523 occurred in the moderately elevated area within higher slope angle where the topographical 524 roughness is maximum. As per the variable importance of RF method, topographical factors were 525 most important compared to the other factors for the LSM.

526 iii) Out of six methods, RF model is the most desirable for its superlative performance in model 527 fitness and validation in both the primary and secondary regions. Besides, novel application of the 528 second most suitable model DB in LSM has been successful which widens its scope in natural 529 hazard mapping.

530 iv) According to landslide susceptibility classes of RF method, about $11 \%$ and $26 \%$ of the study 531 area come under the very high and high landslide vulnerable zones, respectively.

532 The outcomes of this study can be useful to the planners for planning and management of future

533 landslides events. To meet the purpose, RF method can be opted for preparing LSM in alike 534 geographic environment.

\section{Declaration of Interest}

536 The authors declare that they have no known competing financial interests or personal 537 relationships that could have appeared to influence the work reported in this paper. 
539 The authors confirm that the data supporting the findings of this study are available within the article.

541

542

543

544

545

546

547

548

549

550

551

552

553

554

555

556

557

558

559

560

561

562

563

564

565

566

567

568

569

570

\section{References}

Abedini, M., Ghasemian, B., Shirzadi, A., Shahabi, H., Chapi, K., Pham, B.T., Bin Ahmad, B., Tien Bui, D., 2019. A novel hybrid approach of bayesian logistic regression and its ensembles for landslide susceptibility assessment. Geocarto International 34, 1427-1457. https://doi.org/10.1080/10106049.2018.1499820

Aburas, M.M., Ahamad, M.S.S. and Omar, N.Q., 2019. Spatio-temporal simulation and prediction of land-use change using conventional and machine learning models: a review. Environmental Monitoring and Assessment, 191(4), 205. https://doi.org/10.1007/s10661$\underline{019-7330-6}$

Aghdam, I.N., Pradhan, B. and Panahi, M., 2017. Landslide susceptibility assessment using a novel hybrid model of statistical bivariate methods (FR and WOE) and adaptive neuro-fuzzy inference system (ANFIS) at southern Zagros Mountains in Iran. Environmental Earth Sciences, 76(6), 237. DOI: 10.1007/s12665-017-6558-0

Aleotti, P. and Chowdhury, R., 1999. Landslide hazard assessment: summary review and new perspectives. Bulletin of Engineering Geology and the Environment, 58(1), 21-44. https://doi.org/10.1007/s100640050066

Amiri, M., Pourghasemi, H.R., Ghanbarian, G.A. and Afzali, S.F., 2019. Assessment of the importance of gully erosion effective factors using Boruta algorithm and its spatial modeling and mapping using three machine learning algorithms. Geoderma, 340, 55-69. https://doi.org/10.1016/j.geoderma.2018.12.042

Arabameri, A., Rezaei, K., Pourghasemi, H.R., Lee, S. and Yamani, M., 2018. GIS-based gully erosion susceptibility mapping: a comparison among three data-driven models and AHP knowledge-based technique. Environmental Earth Sciences, 77(17), 628. https://doi.org/10.1007/s12665-018-7808-5

Arabameri, A., Pradhan, B., Rezaei, K. and Lee, C.W., 2019. Assessment of landslide susceptibility using statistical-and artificial intelligence-based FR-RF integrated model and multiresolution DEMs. Remote Sensing, 11(9), 999. https://doi.org/10.3390/rs11090999

Arabameri, A., Saha, S., Roy, J., Chen, W., Blaschke, T. and Tien Bui, D., 2020. Landslide susceptibility evaluation and management using different machine learning methods in the Gallicash River Watershed, Iran. Remote Sensing, 12(3), 475. doi:10.3390/rs12030475 
Armaş, I., 2012. Weights of evidence method for landslide susceptibility mapping. Prahova Subcarpathians, Romania. Natural Hazards, 60(3), 937-950. https://doi.org/10.1007/s11069$\underline{011-9879-4}$

Bera, S., Guru, B. and Ramesh, V., 2019. Evaluation of landslide susceptibility models: A comparative study on the part of Western Ghat Region, India. Remote Sensing Applications: Society and Environment, 13, 39-52. https://doi.org/10.1016/j.rsase.2018.10.010

Bonham-Carter, G.F., 1994. Geographic Information Systems for Geoscientists: Modelling with GIS, Elsevier, UK.

Brabb, E.E., Pampeyan, E.H., and Bonilla, M.G., 1978. Landslide susceptibility in San Mateo County, California. US Geological Survey Miscellaneous Field Studies Map, MF-360, Map at 1: 62,500 scale.

Breiman, L. 2001. “Random Forests.” Machine Learning. 45 (1), 5-32.

Budimir, M.E.A., Atkinson, P.M., Lewis, and H.G., 2015. A systematic review of landslide probability mapping using logistic regression. Landslides, 12, 419-436 https://doi.org/10.1007/s10346-014-0550-5

Bui, D.T., Pradhan, B., Lofman, O. and Revhaug, I., 2012. Landslide susceptibility assessment in vietnam using support vector machines, decision tree, and Naive Bayes Models. Mathematical Problems in Engineering, https://doi.org/10.1155/2012/974638

Bui, D.T., Nguyen, Q.P., Hoang, N.D. and Klempe, H., 2017. A novel fuzzy K-nearest neighbor inference model with differential evolution for spatial prediction of rainfall-induced shallow landslides in a tropical hilly area using GIS. Landslides, 14(1), 1-17. DOI 10.1007/s10346$\underline{016-0708-4}$

Bui, D.T., Shahabi, H., Shirzadi, A., Chapi, K., Pradhan, B., Chen, W., Khosravi, K., Panahi, M., Bin Ahmad, B. and Saro, L., 2018. Land subsidence susceptibility mapping in south korea using machine learning algorithms. Sensors, 18(8), 2464. https://doi.org/10.3390/s18082464

Bui, D.T., Shirzadi, A., Shahabi, H., Geertsema, M., Omidvar, E., Clague, J.J., Thai Pham, B., Dou, J., Talebpour Asl, D., Bin Ahmad, B. and Lee, S., 2019. New ensemble models for shallow landslide susceptibility modeling in a semi-arid watershed. Forests, 10(9), 743. https://doi.org/10.3390/f10090743

Carrara, A., Carratelli, E.P., and Merenda, L., 1977. Computer-based data bank and statistical analysis of slope instability phenomena. Zeitschrift für Geomorphologie, 21, 187-222.

Catani, F., Lagomarsino, D., Segoni, S., and Tofani, V., 2013. Landslide susceptibility estimation by random forests technique: sensitivity and scaling issues. Natural Hazards and Earth System Sciences, 13(11), 2815-2831. https://doi.org/10.5194/nhess-13-2815-2013, 2013 
Chapi, K., Singh, V.P., Shirzadi, A., Shahabi, H., Bui, D.T., Pham, B.T. and Khosravi, K., 2017. A novel hybrid artificial intelligence approach for flood susceptibility assessment. Environmental Modelling \& Software, 95, 229-245. https://doi.org/10.1016/j.envsoft.2017.0 6.012

Chen, W., Pourghasemi, H.R., Kornejady, A. and Zhang, N., 2017. Landslide spatial modeling: Introducing new ensembles of ANN, MaxEnt, and SVM machine learning techniques. Geoderma, 305, 314-327. https://doi.org/10.1016/j.geoderma.2017.06.020

Chen, W., Chen, W., Li, H., Hou, E., Wang, S., Wang, G., and Peng, T., 2018a. GIS-based groundwater potential analysis using novel ensemble weights-of-evidence with logistic regression and functional tree models. Science of the Total Environment, 634, 853-867. https://doi.org/10.1016/j.scitotenv.2018.04.055

Chen, W., Peng, J., Hong, H., Shahabi, H., Pradhan, B., Liu, J., Zhu, A.X., Pei, X. and Duan, Z., 2018b. Landslide susceptibility modelling using GIS-based machine learning techniques for Chongren County, Jiangxi Province, China. Science of the total environment, 626, 11211135 .

Chen, W., Chen, Y., Tsangaratos, P., Ilia, I. and Wang, X., 2020. Combining evolutionary algorithms and machine learning models in landslide susceptibility assessments. Remote Sensing, 12(23), 3854. https://doi.org/10.3390/rs12233854

Chen, W. and Li, Y., 2020. GIS-based evaluation of landslide susceptibility using hybrid $\begin{array}{llll}\text { computational intelligence } & \text { models. }\end{array}$ https://doi.org/10.1016/j.catena.2020.104777

Chen, X. and Chen, W., 2021. GIS-based landslide susceptibility assessment using optimized hybrid machine learning methods. Catena, 196, 104833. https://doi.org/10.1016/j.catena.2020.104833

Chen, Y., Chen, W., Janizadeh, S., Bhunia, G.S., Bera, A., Pham, Q.B., Linh, N.T.T., Balogun, A.L. and Wang, X., 2021. Deep learning and boosting framework for piping erosion susceptibility modeling: spatial evaluation of agricultural areas in the semi-arid region. Geocarto International, 1-27. https://doi.org/10.1080/10106049.2021.1892212

Chen, W., Chen, X., Peng, J., Panahi, M. and Lee, S., 2021a. Landslide susceptibility modeling based on ANFIS with teaching-learning-based optimization and Satin bowerbird optimizer. Geoscience Frontiers, 12(1), 93-107. https://doi.org/10.1016/j.gsf.2020.07.012

Chen, W., Lei, X., Chakrabortty, R., Pal, S.C., Sahana, M. and Janizadeh, S., 2021b. Evaluation of different boosting ensemble machine learning models and novel deep learning and boosting framework for head-cut gully erosion susceptibility. Journal of Environmental Management, 284, 112015. https://doi.org/10.1016/j.jenvman.2021.112015 
Cortes, C., Mohri, M. and Syed, U., 2014. Deep boosting. Proceedings of the 31 st International Conference on Machine Learning, Beijing, China, 2014. JMLR: W\&CP volume 32.

Costache, R. and Bui, D.T., 2019. Spatial prediction of flood potential using new ensembles of bivariate statistics and artificial intelligence: A case study at the Putna river catchment of Romania. Science of the Total Environment, 691, 1098-1118. https://doi.org/10.1016/j.scitotenv.2019.07.197

Das, S., Pardeshi, S.D., Kulkarni, P.P., and Doke, A., 2018. Extraction of lineaments from different azimuth angles using geospatial techniques: a case study of Pravara basin, Maharashtra, India. Arabian Journal of Geosciences, 11 (8), 160.

Das, S., 2019. Geospatial mapping of flood susceptibility and hydro-geomorphic response to the floods in Ulhas basin, India. Remote Sensing Applications Society and Environment, 14, 6074.

Das, S., 2020. Flood susceptibility mapping of the Western Ghat coastal belt using multi-source geospatial data and analytical hierarchy process (AHP). Remote Sensing Applications Society and Environment 20, 100379.

Dou, J., Paudel, U., Oguchi, T., Uchiyama, S., and Hayakawa, Y.S., 2015. Shallow and DeepSeated Landslide Differentiation using support Vector Machines: a Case Study of the Chuetsu Area, Japan. Terrestrial Atmospheric and Oceanic Sciences, 26, 227. https://doi.org/10.3319/TAO.2014.12.02.07(EOSI)

Elith, J., Leathwick, J.R. and Hastie, T., 2008. A working guide to boosted regression trees. Journal of Animal Ecology, 77(4), 802-813. https://doi.org/10.1111/j.1365-2656.2008.01390.x

Friedman, J.H., and Tibshirani, R., 2000. Additive logistic regression: a statistical view of boosting (with discussion and a rejoinder by the authors). The Annals of Statistics, 28(2), 337-407.

Friedman, J.H., 2001. Greedy function approximation: a gradient boosting machine. Annals of Statistics, 1189-1232.

Friedman, J.H., 2002. Stochastic gradient boosting. Computational statistics \& data analysis, 38(4), 367-378. https://doi.org/10.1016/S0167-9473(01)00065-2

Gallant, J.C., 2000. Terrain analysis: principles and applications. John Wiley \& Sons.

Guzzetti, F., Carrara, A., Cardinali, M. and Reichenbach, P., 1999. Landslide hazard evaluation: a review of current techniques and their application in a multi-scale study, Central Italy. Geomorphology, 31, 181-216. https://doi.org/10.1016/S0169-555X(99)00078-1

Guzzetti, F., Reichenbach, P., Cardinali, M., Galli, M., and Ardizzone, F., 2005. Probabilistic landslide hazard assessment at the basin scale. Geomorphology, 72, 272-299. http://dx.doi.org/10.1016/j.geomorph.2005.06.002 
Guzzetti, F., Reichenbach, P., Ardizzone, F., Cardinali, M., and Galli, M., 2006. Estimating the quality of landslide susceptibility models. Geomorphology, 81, 166-184.

Hansen, A., 1984. Landslide hazard analysis. In: Brunsden, D., Prior, D.B. (Eds.), Slope Instability. Wiley \& Sons, New York, 523-602

Hong, H., Liu, J., Bui, D.T., Pradhan, B., Acharya, T.D., Pham, B.T., Zhu, A.X., Chen, W. and Ahmad, B.B., 2018. Landslide susceptibility mapping using J48 Decision Tree with AdaBoost, Bagging and Rotation Forest ensembles in the Guangchang area (China). Catena, 163, 399-413. https://doi.org/10.1016/j.catena.2018.01.005

Hosseinalizadeh, M., Kariminejad, N., Rahmati, O., Keesstra, S., Alinejad, M. and Behbahani, A.M., 2019. How can statistical and artificial intelligence approaches predict piping erosion susceptibility?. Science of the Total Environment, 646, 1554-1566. https://doi.org/10.1016/j.scitotenv.2018.07.396

Jamali, A., 2020. Land use land cover modeling using optimized machine learning classifiers: a case study of Shiraz, Iran. Modeling Earth Systems and Environment, 1-12. https://doi.org/10.1007/s40808-020-00859-x

Kadavi, P.R., Lee, C.W. and Lee, S., 2018. Application of ensemble-based machine learning models to landslide susceptibility mapping. Remote Sensing, 10(8), 1252. https://doi.org/10.3390/rs 10081252

Khosravi, K., Pham, B.T., Chapi, K., Shirzadi, A., Shahabi, H., Revhaug, I., Prakash, I. and Bui, D.T., 2018. A comparative assessment of decision trees algorithms for flash flood susceptibility modeling at Haraz watershed, northern Iran. Science of the Total Environment, 627, 744-755. https://doi.org/10.1016/j.scitotenv.2018.01.266

Kim, J.C., Lee, S., Jung, H.S., and Lee, S., 2018. Landslide susceptibility mapping using random forest and boosted tree models in Pyeong-Chang, Korea. Geocarto International, 33(9), 1000-1015. https://doi.org/10.1080/10106049.2017.1323964

Kursa, M.B. and Rudnicki, W.R., 2010. Feature selection with the Boruta package. Journal of Statistical Software, 36(11), 1-13.

Landis, J.R., Koch, G.G., 1977. The measurement of observer agreement for categorical data. biometrics $159 \mathrm{e} 174$.

Lawrence, R., Bunn, A., Powell, S. and Zambon, M., 2004. Classification of remotely sensed imagery using stochastic gradient boosting as a refinement of classification tree analysis. Remote Sensing of Environment, 90(3), 331-336. https://doi.org/10.1016/j.rse.2004.01.007

Lee, S., Ryu, J., Min, K., and Won, J., 2001. Development of two artificial neural network methods for landslide susceptibility analysis. In: IGARSS 2001. Scanning the Present and Resolving the Future. Proceedings. IEEE 2001 International Geoscience and Remote Sensing 
Symposium,(Cat.No.01CH37217).5.2364-2366. https://doi.org/10.1109/IGARSS.2001.978003

Lee, S. and Choi, J., 2004a. Landslide susceptibility mapping using GIS and the weight-ofevidence model. International Journal of Geographical Information Science, 18(8), 789-814. https://doi.org/10.1080/13658810410001702003

Lee, S., Ryu, J.H., Won, J.S. and Park, H.J., 2004b. Determination and application of the weights for landslide susceptibility mapping using an artificial neural network. Engineering Geology, 71, 289-302. https://doi.org/10.1016/S0013-7952(03)00142-X

Miner, A., Vamplew, P., Windle, D.J., Flentje, P., and Warner, P., 2010. A Comparative Study of Various Data Mining Techniques as Applied to the Modeling of Landslide Susceptibility on the Bellarine Peninsula. Geologically Active, Proceedings of the 11th IAEG Congress of the International Association of Engineering Geology and the Environment, Auckland, New Zealand.

Moisen, G.G., Freeman, E.A., Blackard, J.A., Frescino, T.S., Zimmermann, N.E. and Edwards Jr, T.C., 2006. Predicting tree species presence and basal area in Utah: a comparison of stochastic gradient boosting, generalized additive models, and tree-based methods. Ecological Modelling, 199(2), 176-187. https://doi.org/10.1016/j.ecolmodel.2006.05.021

Montgomery, D.R., and Dietrich, W.E., 1994. A physically based model for the topographic control of shallow landsliding. Water Resources Research, 30 (4), 1153-1171. http://dx.doi.org/10.1029/93wr02979

Moore, I.D., and Burch, G.J., 1986. Physical basis of the length-slope factor in the universal soil loss equation 1. Soil Science Society of America Journal, 50(5), 1294-1298. doi:10.2136/sssaj1986.03615995005000050042x

Moore, I.D. and Grayson, R.B., 1991. Terrain-based catchment partitioning and runoff prediction using vector elevation data. Water Resources Research, 27(6), 1177-1191. https://doi.org/10.1029/91WR00090

Moore, I.D., Grayson, R.B., and Ladson, A.R., 1991. Digital terrain modelling: a review of hydrological, geomorphological, and biological applications. Hydrological Processes, 5(1), 3-30. https://doi.org/10.1002/hyp.3360050103

Naghibi, S.A., Pourghasemi, H.R., and Dixon, B., 2016. GIS-based groundwater potential mapping using boosted regression tree, classification and regression tree, and random forest machine learning models in Iran. Environmental Monitoring and Assessment, 188, 44. https://doi.org/10.1007/s10661-015-5049-6

Naghibi, S.A., Ahmadi, K., and Daneshi, A., 2017. Application of support vector machine, random forest, and genetic algorithm optimized random forest models in groundwater potential 
Naghibi, S.A., Dolatkordestani, M., Rezaei, A., Amouzegari, P., Heravi, M.T., Kalantar, B. and Pradhan, B., 2019. Application of rotation forest with decision trees as base classifier and a novel ensemble model in spatial modeling of groundwater potential. Environmental Monitoring and Assessment, 191(4), 248. https://doi.org/10.1007/s10661-019-7362-y

Nakileza, B.R. and Nedala, S., 2020. Topographic influence on landslides characteristics and implication for risk management in upper Manafwa catchment, Mt Elgon Uganda. Geoenvironmental Disasters, 7(1), 1-13. https://doi.org/10.1186/s40677-020-00160-0

Nguyen, Q.K., Tien Bui, D., Hoang, N.D., Trinh, P.T., Nguyen, V.H. and Yilmaz, I., 2017. A novel hybrid approach based on instance based learning classifier and rotation forest ensemble for spatial prediction of rainfall-induced shallow landslides using GIS. Sustainability, 9(5), 813. https://doi.org/10.3390/su9050813

Nohani, E., Moharrami, M., Sharafi, S., Khosravi, K., Pradhan, B., Pham, B.T., Lee, S. and M Melesse, A., 2019. Landslide susceptibility mapping using different GIS-based bivariate models. Water, 11(7), 1402. https://doi.org/10.3390/w11071402fgull

Oh, H.J., Syifa, M., Lee, C.W. and Lee, S., 2019. Land subsidence susceptibility mapping using bayesian, functional, and meta-ensemble machine learning models. Applied Sciences, 9(6), 1248. https://doi.org/10.3390/app9061248

Panahi, M., Gayen, A., Pourghasemi, H.R., Rezaie, F. and Lee, S., 2020. Spatial prediction of landslide susceptibility using hybrid support vector regression (SVR) and the adaptive neurofuzzy inference system (ANFIS) with various metaheuristic algorithms. Science of the Total Environment, 139937. https://doi.org/10.1016/j.scitotenv.2020.139937

Park, S. and Kim, J., 2019. Landslide susceptibility mapping based on random forest and boosted regression tree models, and a comparison of their performance. Applied Sciences, 9(5), 942. https://doi.org/10.3390/app9050942

Pham, B.T., Prakash, I., Dou, J., Singh, S.K., Trinh, P.T., Tran, H.T., Le, T.M., Van Phong, T., Khoi, D.K., Shirzadi, A. and Bui, D.T., 2020a. A novel hybrid approach of landslide susceptibility modelling using rotation forest ensemble and different base classifiers. Geocarto International, 35(12), 1267-1292. https://doi.org/10.1080/10106049.2018.1559885

Pham, B.T., Avand, M., Janizadeh, S., Phong, T.V., Al-Ansari, N., Ho, L.S., Das, S., Le, H.V., Amini, A., Bozchaloei, S.K., Jafari, F., Prakash, I., 2020b. GIS based hybrid computational approaches for flash flood susceptibility assessment. Water, 12 (3), 686. https://doi.org/10.3390/w12030683

Phong, T.V., Phan, T.T., Prakash, I., Singh, S.K., Shirzadi, A., Chapi, K., Ly, H.B., Ho, L.S., Quoc, N.K. and Pham, B.T., 2019. Landslide susceptibility modeling using different artificial 
intelligence methods: A case study at Muong Lay district, Vietnam. Geocarto International, 1-24. https://doi.org/10.1080/10106049.2019.1665715

Polikar, R., DePasquale, J., Mohammed, H.S., Brown, G. and Kuncheva, L.I., 2010. Learn++. MF: A random subspace approach for the missing feature problem. Pattern Recognition, 43(11), 3817-3832. https://doi.org/10.1016/j.patcog.2010.05.028

Pourghasemi, H.R., Mohammady, M. and Pradhan, B., 2012. Landslide susceptibility mapping using index of entropy and conditional probability models in GIS: Safarood Basin, Iran. Catena, 97, 71-84. https://doi.org/10.1016/j.catena.2012.05.005

Pourghasemi, H.R., Moradi, H.R., and Aghda, S.F., 2013. Landslide susceptibility mapping by binary logistic regression, analytical hierarchy process, and statistical index models and assessment of their performances. Natural Hazards, 69(1), 749-779. https://doi.org/10. 1007/s11069-013-0728-5

Pourghasemi, H.R., Sadhasivam, N., Kariminejad, N. and Collins, A.L., 2020. Gully erosion spatial modelling: Role of machine learning algorithms in selection of the best controlling factors and modelling process. Geoscience Frontiers, https://doi.org/10.1016/j.gsf.2020.03.005

Pradhan, B., 2013. A comparative study on the predictive ability of the decision tree, support vector machine and neuro-fuzzy models in landslide susceptibility mapping using GIS. Computer \& Geoscience, 51, 350-365. https://doi.org/10.1016/j.cageo.2012.08.023

Prasad, P., Loveson, V.J., Kotha, M., and Yadav, R., 2020. Application of machine learning techniques in groundwater potential mapping along the west coast of India. GIScience \& Remote Sensing, 57(6), 735-752. https://doi.org/10.1080/15481603.2020.1794104

Prasad, P., Loveson, V.J., Das, B. and Kotha, M., 2021. Novel ensemble machine learning models in flood susceptibility mapping. Geocarto International, 1-23. https://doi.org/10.1080/10106049.2021.1892209

Rahmati, O., Pourghasemi, H.R. and Zeinivand, H., 2015. Flood susceptibility mapping using frequency ratio and weights-of-evidence models in the Golastan Province, Iran. Geocarto International, 31(1), 42-70. https://doi.org/10.1080/10106049.2015.1041559

Rahmati, O., Pourghasemi, H.R., and Melesse, A.M., 2016. Application of GIS-based data driven random forest and maximum entropy models for groundwater potential mapping: a case study at Mehran Region, Iran. Catena, 137, 360-372. https://doi.org/10.1016/j.catena.2015. 10.010

Regmi, N.R., Giardino, J.R. and Vitek, J.D., 2010. Modeling susceptibility to landslides using the weight of evidence approach: Western Colorado, USA. Geomorphology, 115(1-2), 172-187. https://doi.org/10.1016/j.geomorph.2009.10.002 
Reichenbach, P., Rossi, M., Malamud, B.D., Mihir, M. and Guzzetti, F., 2018. A review of statistically-based landslide susceptibility models. Earth Science Reviews, 180, 60-91. https://doi.org/10.1016/j.earscirev.2018.03.001

Rodriguez, J.J., Kuncheva, L.I. and Alonso, C.J., 2006. Rotation forest: A new classifier ensemble method. IEEE transactions on pattern analysis and machine intelligence, 28(10), 1619-1630. doi: 10.1109/TPAMI.2006.211

Rossi, M., Guzzetti, F., Reichenbach, P., Mondini, A.C., and Peruccacci, S., 2010. Optimal landslide susceptibility zonation based on multiple forecasts. Geomorphology, 114, 129-142. https://doi.org/10.1016/j.geomorph.2009.06.020

Shahabi, H., Shirzadi, A., Ghaderi, K., Omidvar, E., Al-Ansari, N., Clague, J.J., Geertsema, M., Khosravi, K., Amini, A., Bahrami, S. and Rahmati, O., 2020. Flood Detection and Susceptibility Mapping Using Sentinel-1 Remote Sensing Data and a Machine Learning Approach: Hybrid Intelligence of Bagging Ensemble Based on K-Nearest Neighbor Classifier. Remote Sensing, 12(2), 266. https://doi.org/10.3390/rs12020266

Stambaugh, M.C. and Guyette, R.P., 2008. Predicting spatio-temporal variability in fire return intervals using a topographic roughness index. Forest Ecology and Management, 254(3), 463473. https://doi.org/10.1016/j.foreco.2007.08.029

Sun, P., Reid, M.D. and Zhou, J., 2014. An improved multiclass LogitBoost using adaptive-onevs-one. Machine learning, 97(3), 295-326. https://doi.org/10.1007/s10994-014-5434-3

Suzen, M.L., and Doyuran, V., 2003. A comparison of the GIS based landslide susceptibility assessment methods: multivariate versus bivariate. Environmental Geology, 45, 665-679.

Tehrany, M.S., Pradhan, B. and Jebur, M.N., 2013. Spatial prediction of flood susceptible areas using rule based decision tree (DT) and a novel ensemble bivariate and multivariate statistical models in GIS. Journal of Hydrology, 504, 69-79. https://doi.org/10.1016/j.jhydrol. 2013. $\underline{09.034}$

Tehrany, M.S., Jones, S., Shabani, F., Martínez-Álvarez, F. and Bui, D.T., 2018. A novel ensemble modeling approach for the spatial prediction of tropical forest fire susceptibility using logitboost machine learning classifier and multi-source geospatial data. Theoretical and Applied Climatology, 137, 637-653. https://doi.org/10.1007/s10661-019-7362-y

UNISDR, C., 2015. The human cost of natural disasters: A global perspective.

Van W.C.J., Rengers, N., and Soeters, R., 2003. Use of Geomorphological information in indirect landslide assessment. Natural Hazards, 30, 399-419.

Van W.C.J., Van Asch, T.W., and Soeters, R., 2006. Landslide hazard and risk zonation-Why is it still so difficult? Bull. Eng. Geol. Environ. 65, 167-184. 
Van W.C.J., Castellanos, E., and Kuriakose, S.L., 2008. Spatial data for landslide susceptibility, hazard, and vulnerability assessment: an overview. Engineering Geology, 102, 112-131. http://dx.doi.org/10.1016/j.enggeo.2008.03.010

Wang, Y., Fang, Z. and Hong, H., 2019. Comparison of convolutional neural networks for landslide susceptibility mapping in Yanshan County, China. Science of the Total Environment, 666, 975-993. https://doi.org/10.1016/j.scitotenv.2019.02.263

Wang, Y., Sun, D., Wen, H., Zhang, H. and Zhang, F., 2020. Comparison of random forest model and frequency ratio model for landslide susceptibility mapping (LSM) in Yunyang County (Chongqing, China). International journal of environmental research and public health, 17(12), 4206. https://doi.org/10.3390/ijerph17124206

Wu, Y., Ke, Y., Chen, Z., Liang, S., Zhao, H. and Hong, H., 2020. Application of alternating decision tree with AdaBoost and bagging ensembles for landslide susceptibility mapping. Catena, 187, 104396. https://doi.org/10.1016/j.catena.2019.104396

Yalcin, A., 2008. GIS-based landslide susceptibility mapping using analytical hierarchy process and bivariate statistics in Ardesen (Turkey): comparisons of results and confirmations. Catena, 72(1), 1-12.

Yesilnacar, E. and Topal, T., 2005. Landslide susceptibility mapping: a comparison of logistic regression and neural networks methods in a medium scale study, Hendek region (Turkey). Engineering Geology, 79, 251-266. https://doi.org/10.1016/j.enggeo.2005.02.002

Yilmaz, I., 2009. Landslide susceptibility mapping using frequency ratio, logistic regression, artificial neural networks and their comparison: a case study from Kat landslides (TokatTurkey). Computers \& Geosciences, 35(6), 1125-1138. https://doi.org/10.1016/j.cageo. 2008. $\underline{08.007}$

Youssef, A.M., Pourghasemi, H.R., Pourtaghi, Z.S., and Al-Katheeri, M.M., 2016. Landslide susceptibility mapping using random forest, boosted regression tree, classification and regression tree, and general linear models and comparison of their performance at Wadi Tayyah Basin, Asir Region, Saudi Arabia. Landslides, 13(5), 839-856. https://doi.org/ $\underline{10.1007 / \mathrm{s} 10346-015-0614}$

Zhao, X. and Chen, W., 2020. Optimization of computational intelligence models for landslide susceptibility evaluation. Remote Sensing, 12(14), 2180. https://doi.org/10.3390/rs12142180

Zhou, J., Shi, X.Z., Huang, R.D., Qiu, X.Y. and Chen, C., 2016. Feasibility of stochastic gradient boosting approach for predicting rockburst damage in burst-prone mines. Transactions of Nonferrous Metals Society of China, 26(7), 1938-1 


\section{List of caption for figures}

Figure 1 Location maps of the study area (a), and secondary region (b)

Figure 2 Recent field photos of occurred landslides in the study area

Figure 3 Thematic layers of the Landslide triggering factors (a) slope, (b) elevation, (c) LS, (d) TRI, (e) SPI, (f) TWI, (g) drainage density, (h) road density, (i) lineament density, (j) NDVI, (k) rainfall, (l) lithology, (m) geomorphology, and (n) soil. The current methodology of the research

Figure 4 The current methodology of the research

Figure 5 Feature selection by boruta approach (a), variables importance in landslide susceptibility mapping (b)

Figure 6 ROC curve of the models in study area (a), secondary area (b)

Figure 7 Landslide susceptibility mapping derived from (a) RF, (b) DB, (c) SGB, (d) RoF, (e) BRT, and (f) LB models

Figure 8 Area of different landslide susceptibility classes of the models 
Figures
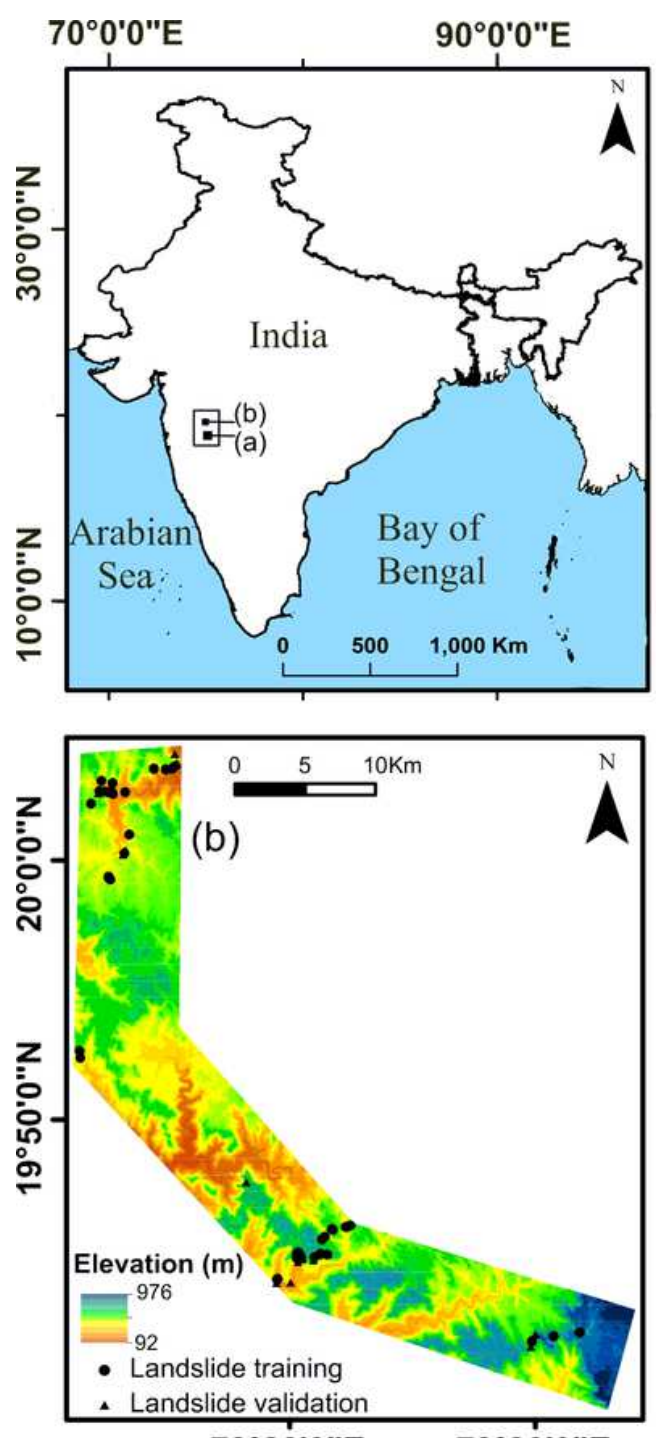

$73^{\circ} 20^{\prime} 0^{\prime \prime} \mathrm{7} \quad 73^{\circ} 30^{\prime} 0{ }^{\prime \prime} \mathrm{E}$

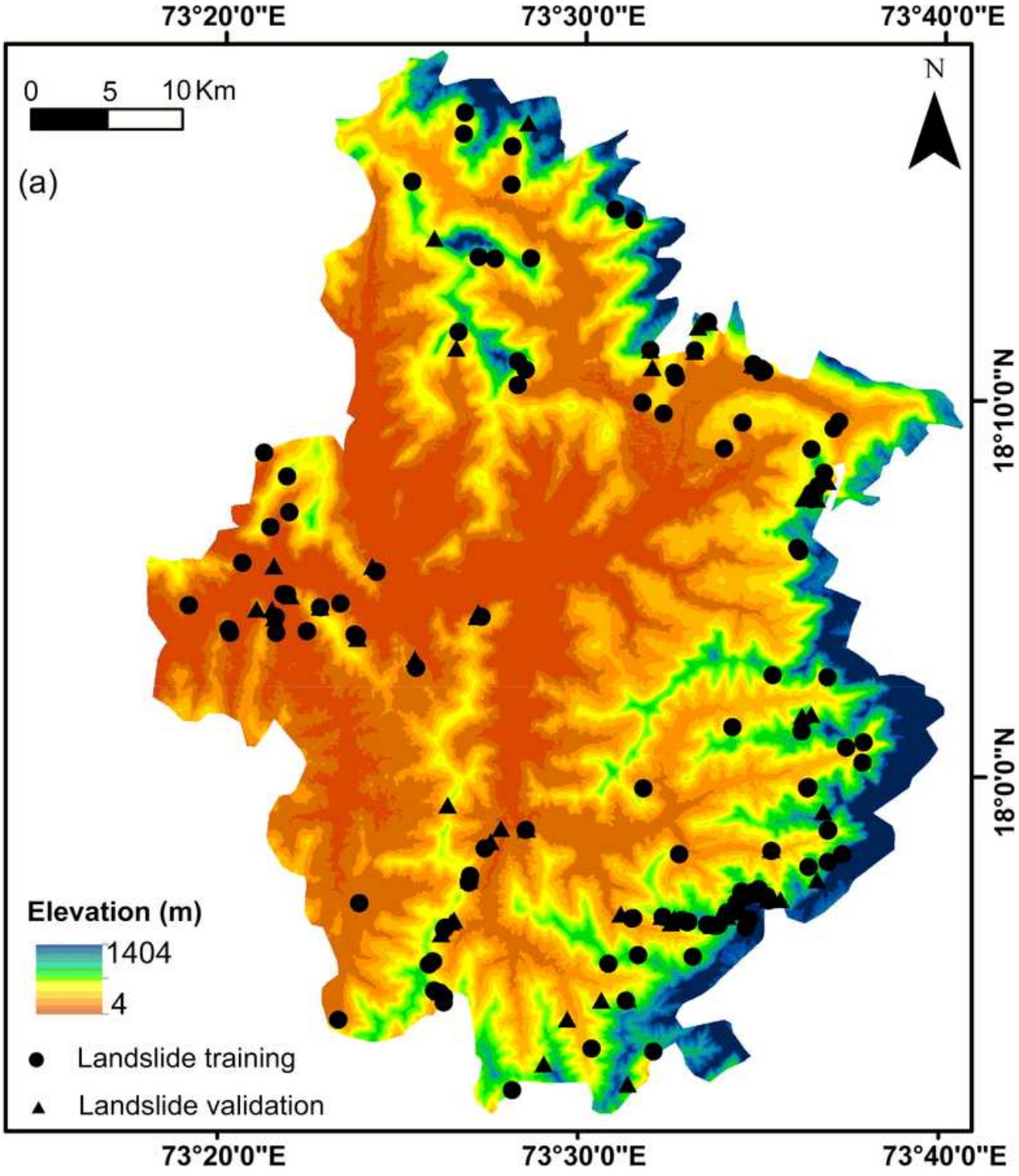

Figure 1

Location maps of the study area (a), and secondary region (b) 

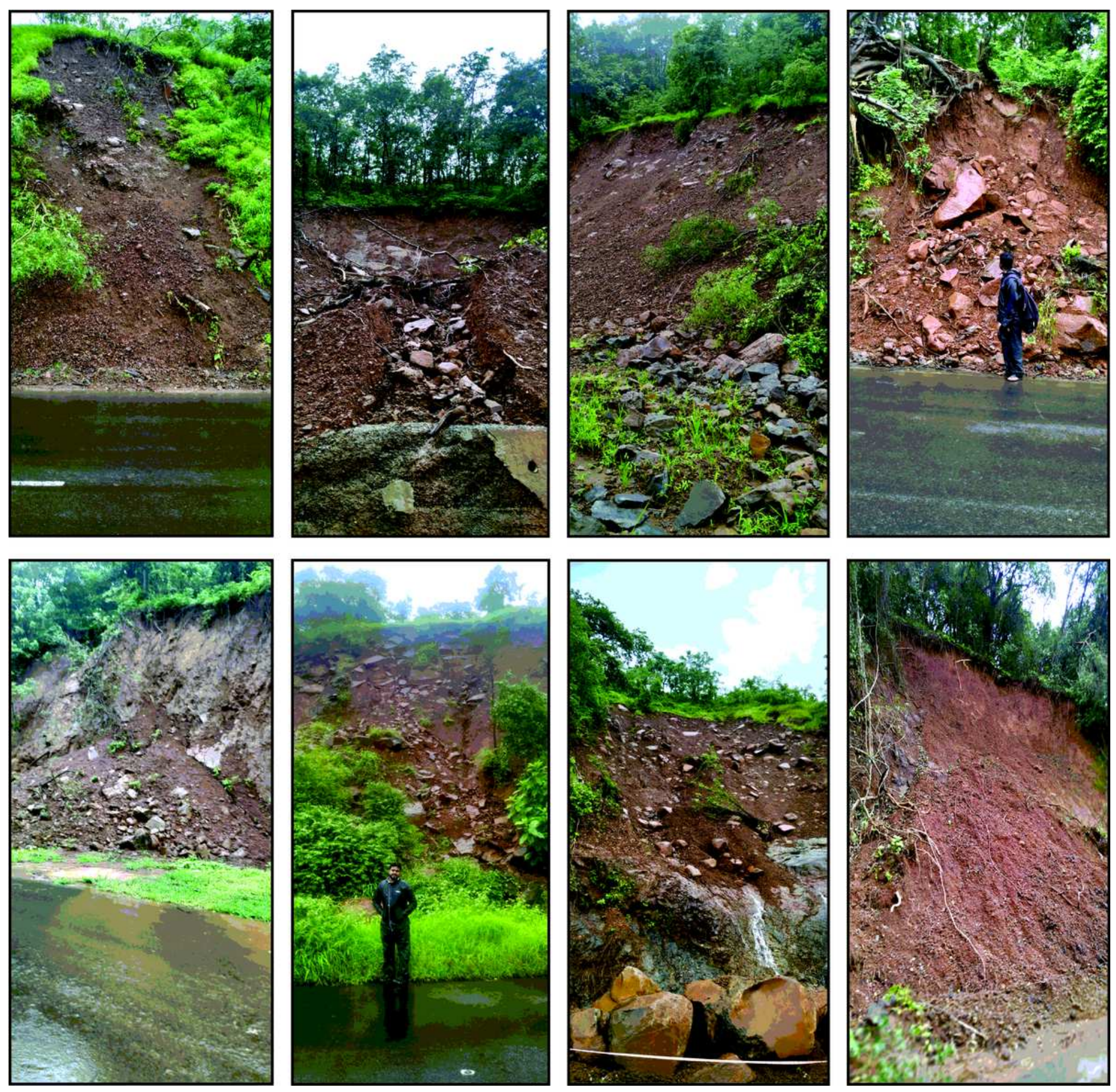

Figure 2

Recent field photos of occurred landslides in the study area 


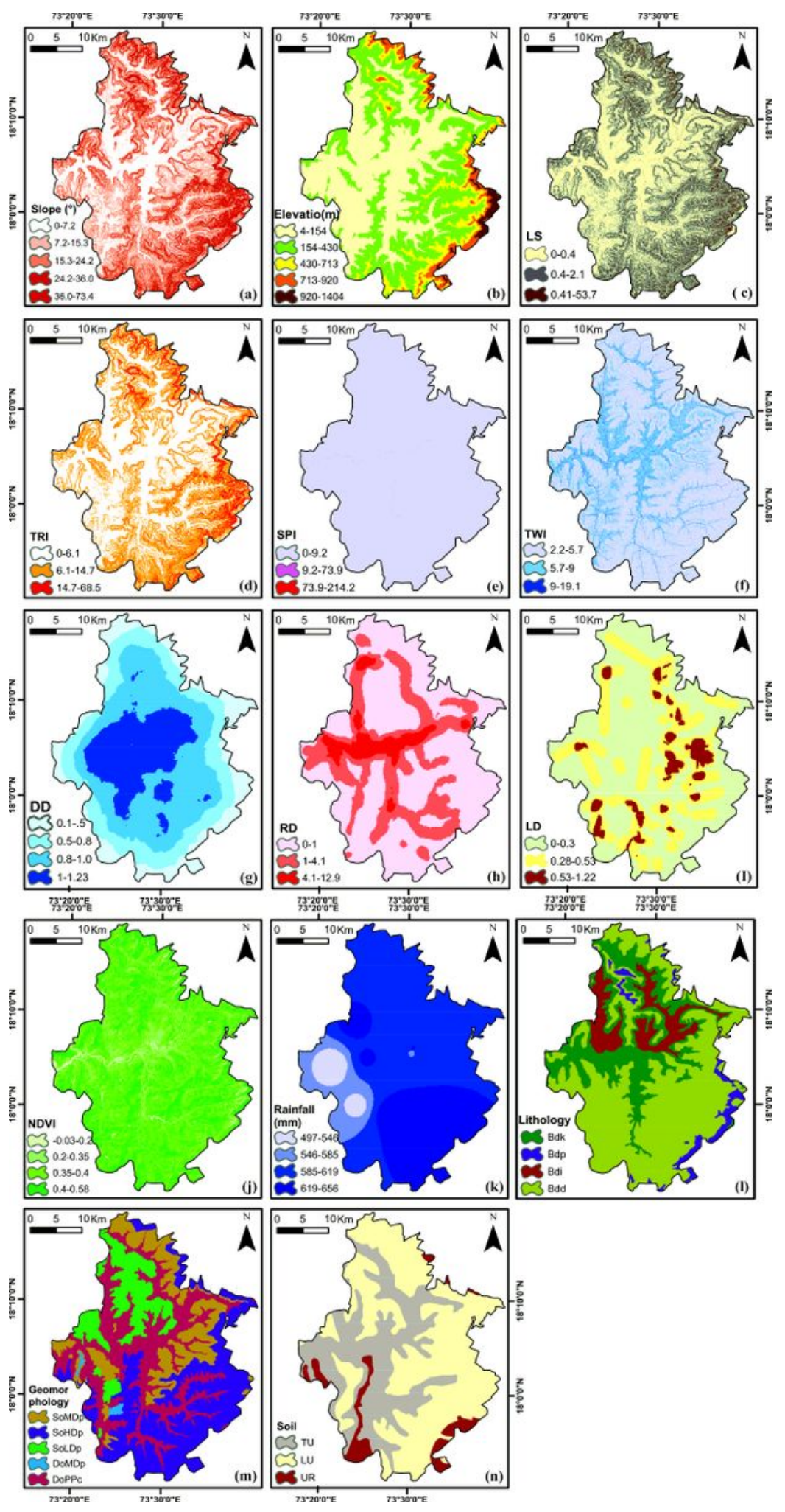

Figure 3

Thematic layers of the Landslide triggering factors (a) slope, (b) elevation, (c) LS, (d) TRI, (e) SPI, (f) TWI, (g) drainage density, (h) road density, (i) lineament density, (j) NDVI, (k) rainfall, (I) lithology, (m) geomorphology, and (n) soil. The current methodology of the research 


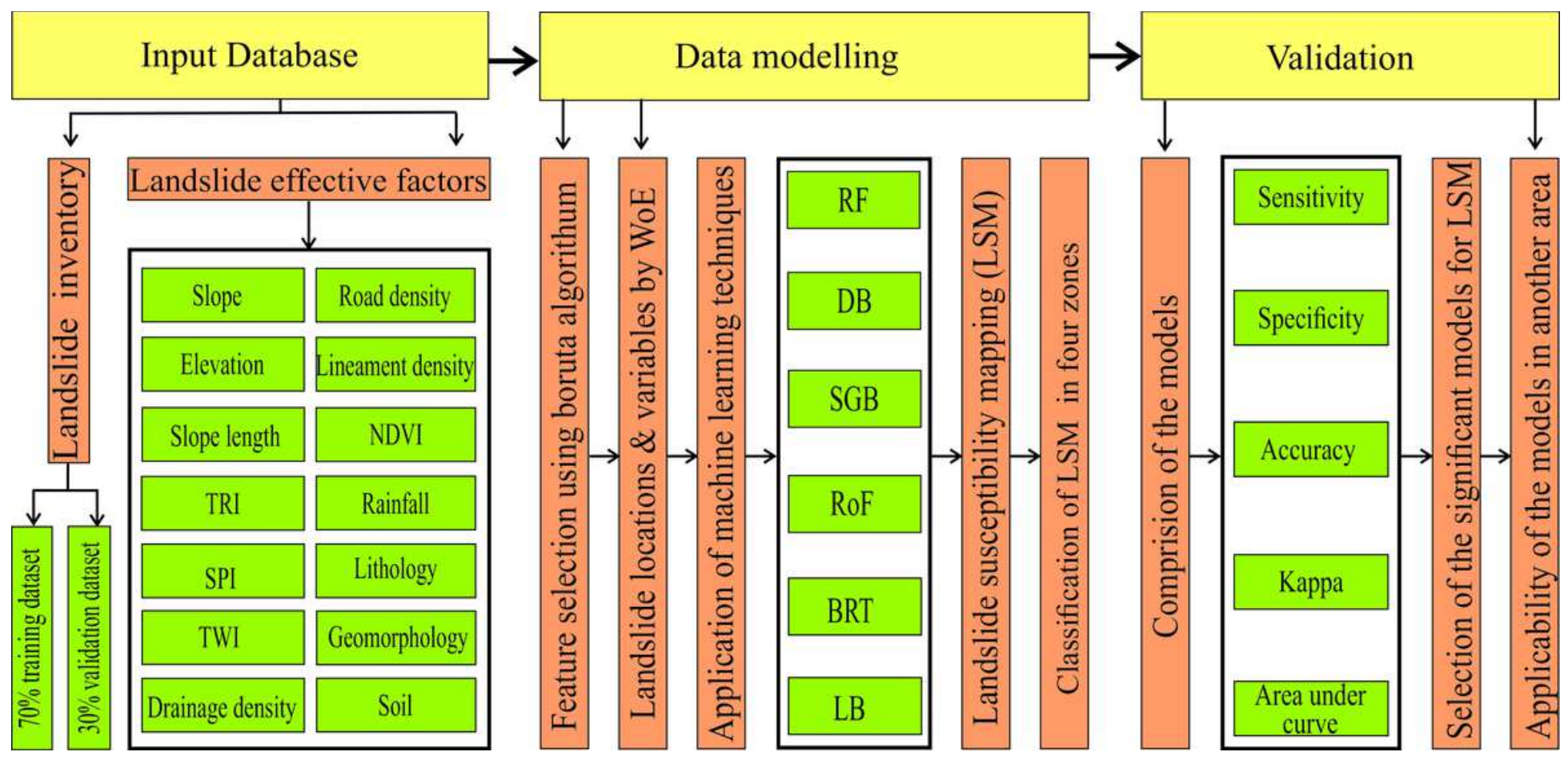

Figure 4

The current methodology of the research

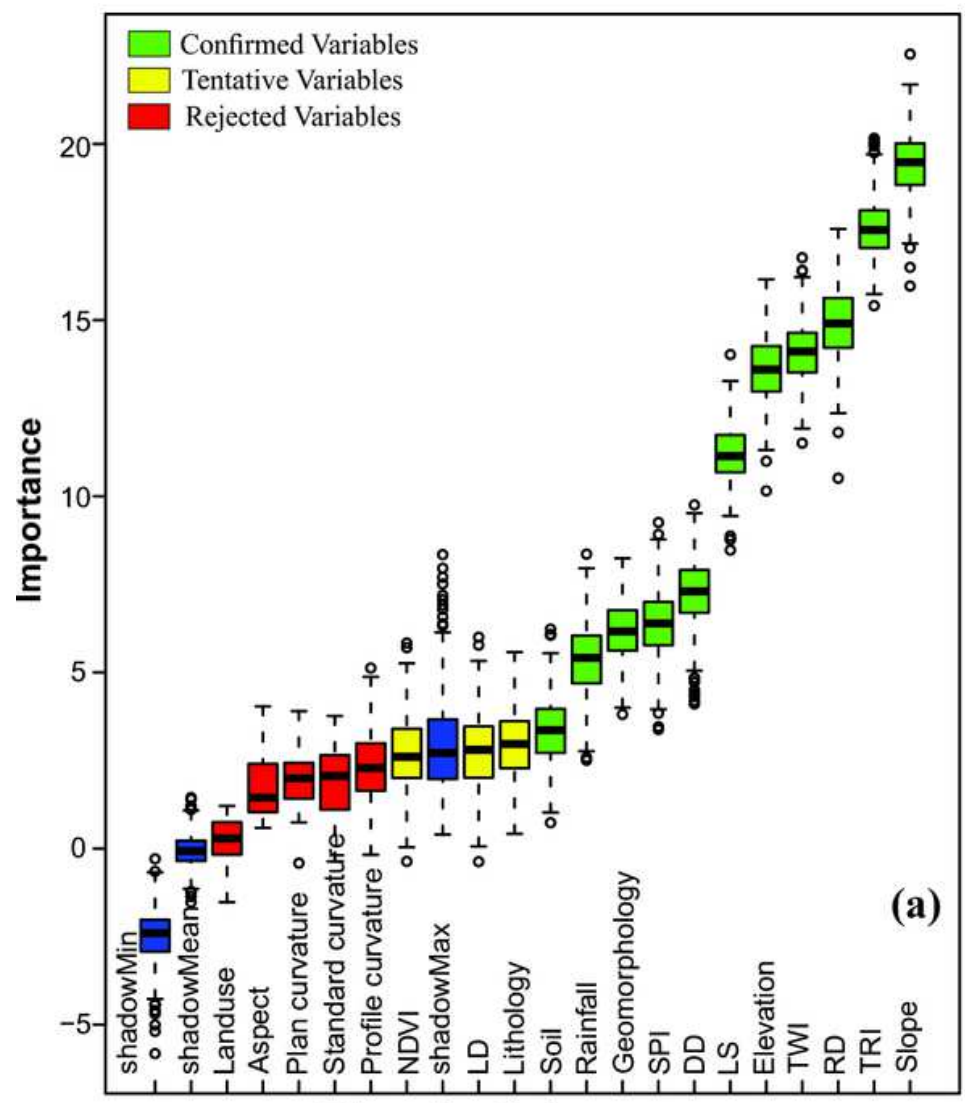

Triggering factors

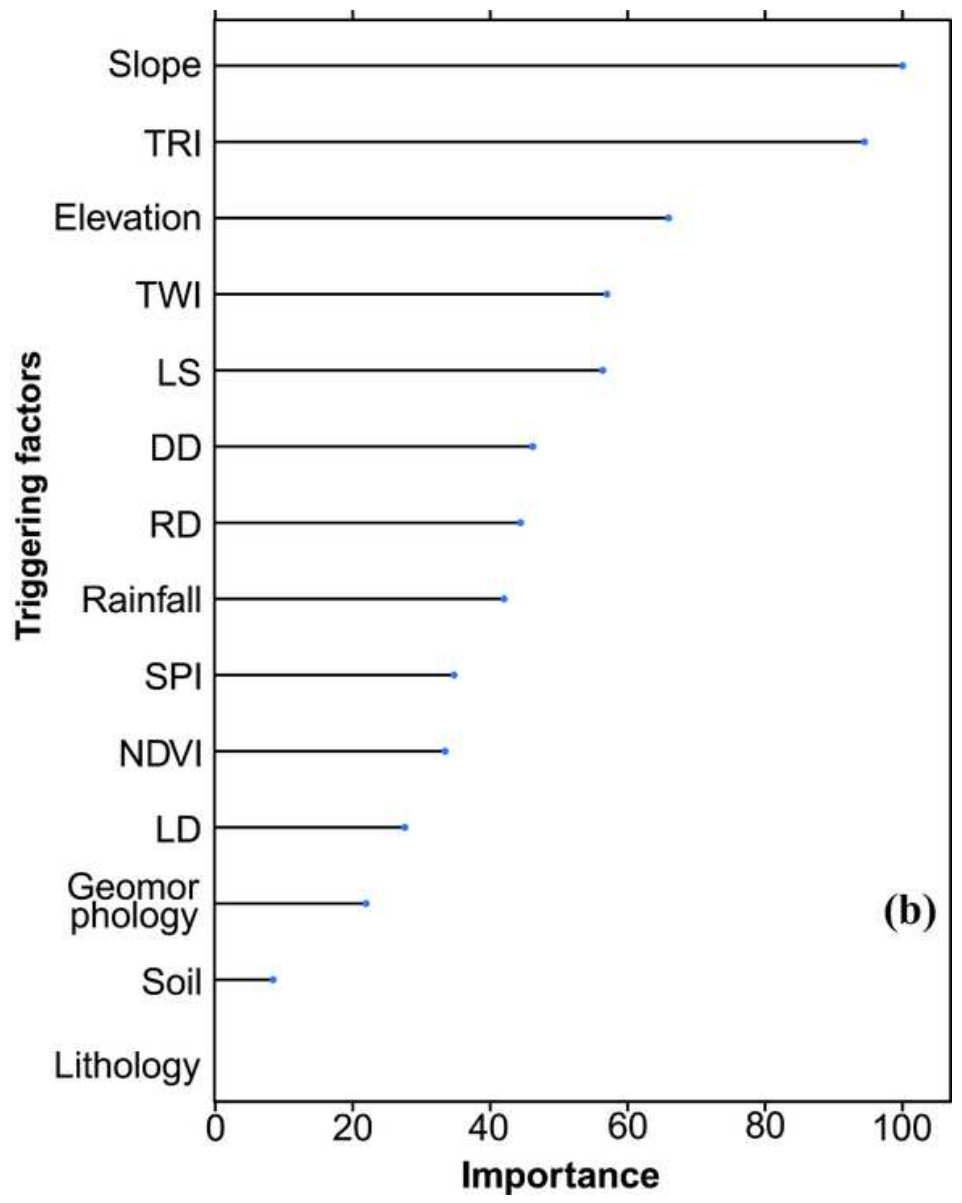

Figure 5 
Feature selection by boruta approach (a), variables importance in landslide susceptibility mapping (b)
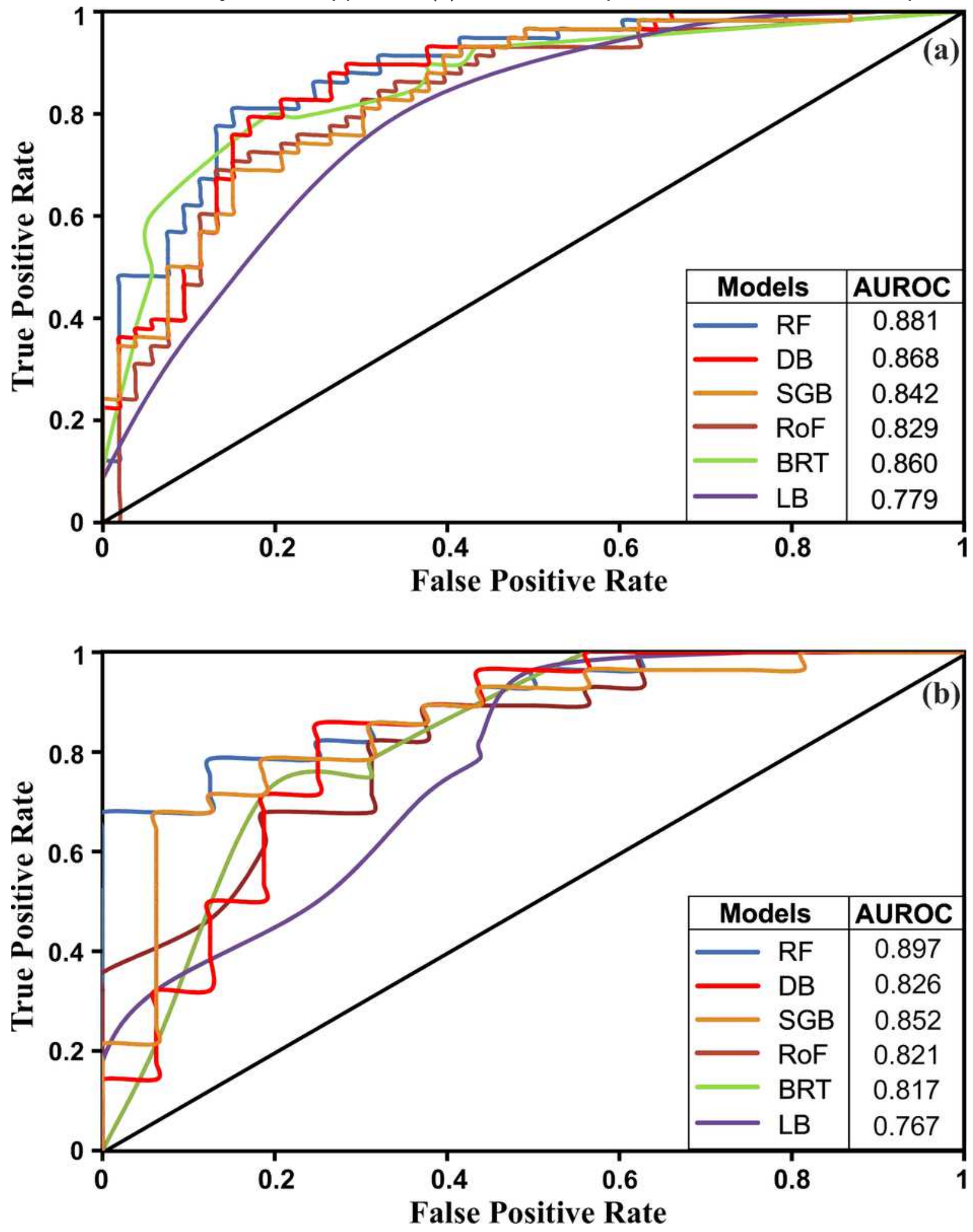

Figure 6

ROC curve of the models in study area (a), secondary area (b) 

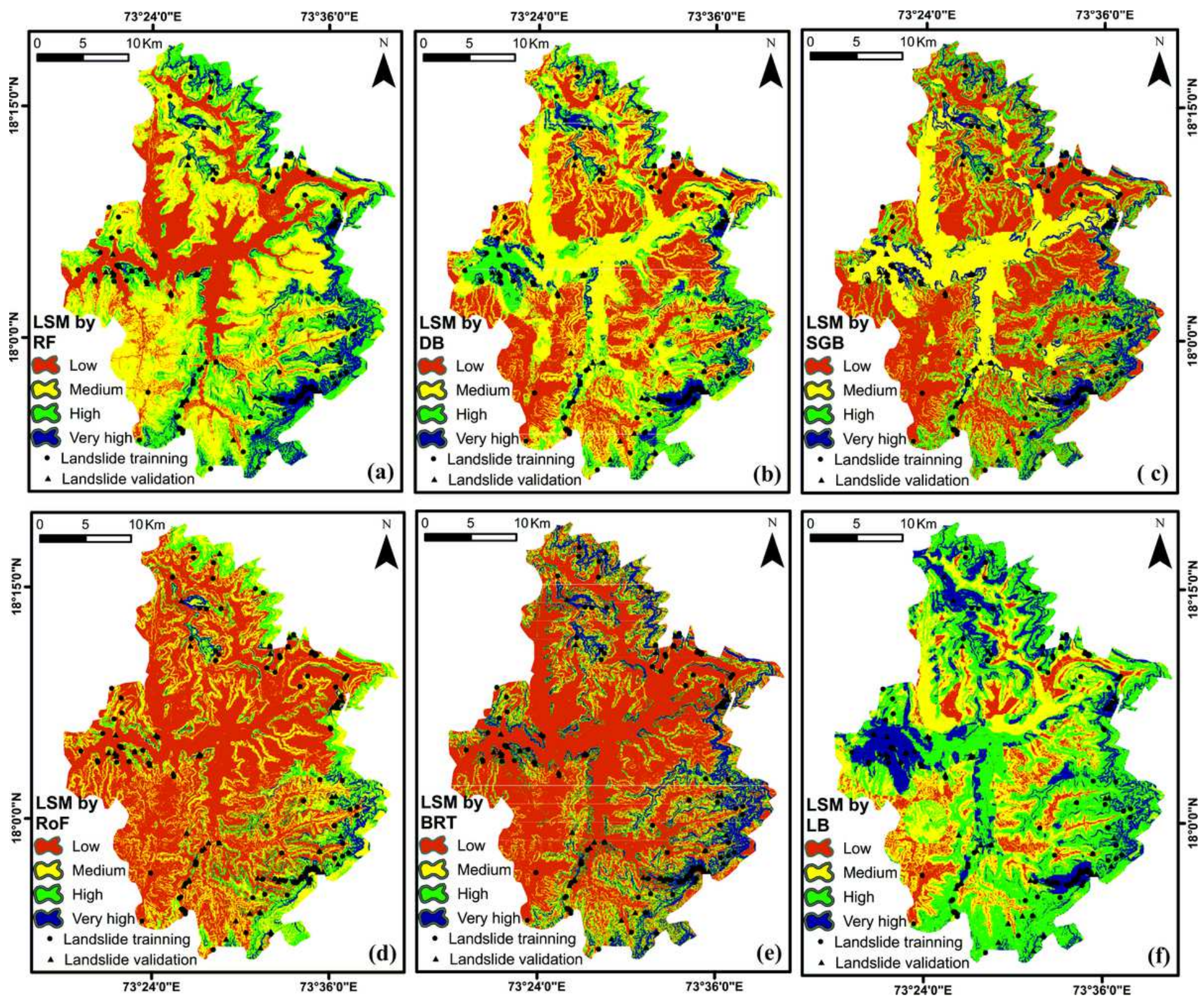

Figure 7

Landslide susceptibility mapping derived from (a) RF, (b) DB, (c) SGB, (d) RoF, (e) BRT, and (f) LB models 


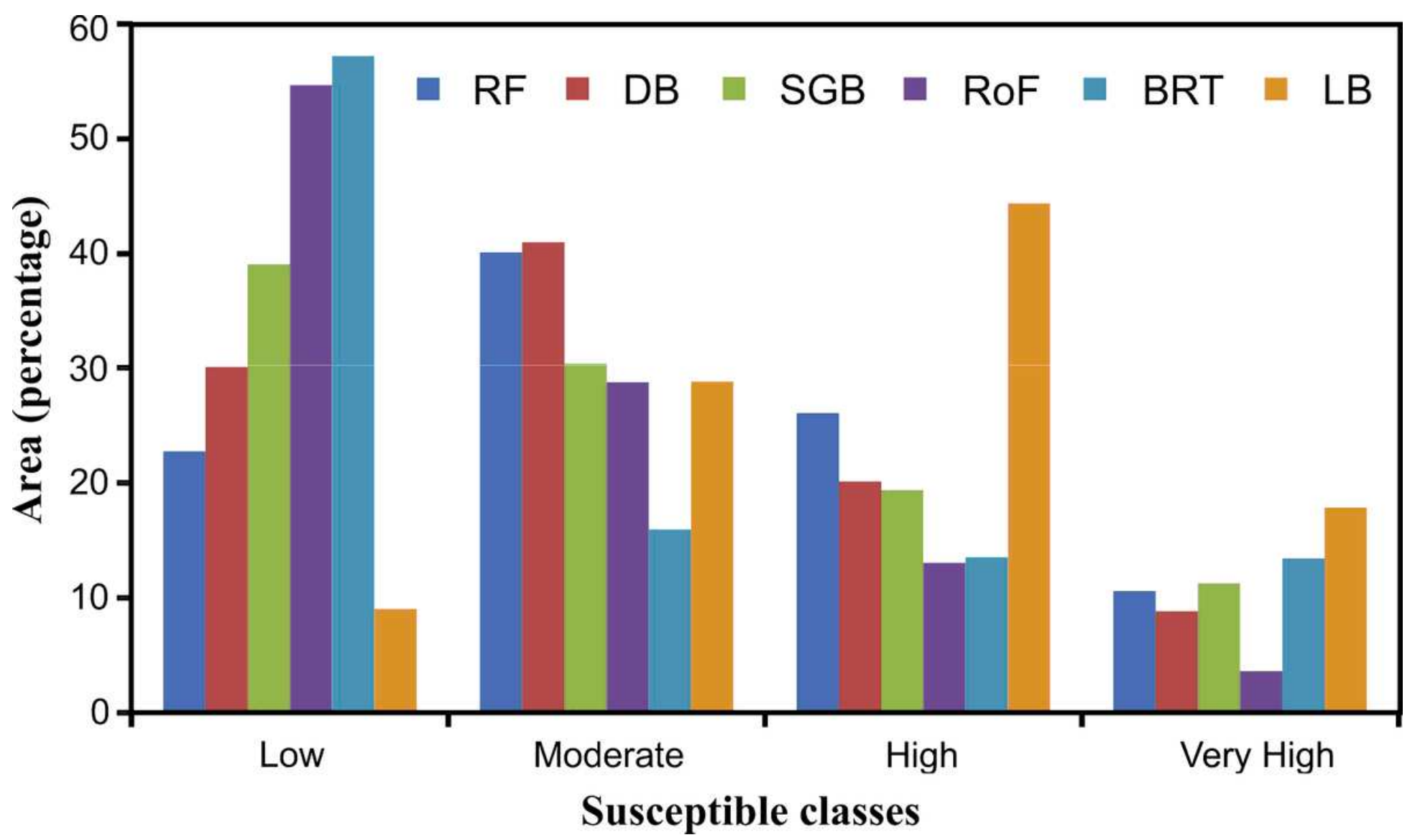

Figure 8

Area of different landslide susceptibility classes of the models

\section{Supplementary Files}

This is a list of supplementary files associated with this preprint. Click to download.

- Database.docx

- InventoryofLandslide.pdf 